\title{
The PPAR- $\gamma$ antagonist T007 inhibits RANKL-induced osteoclastogenesis and counteracts OVX-induced bone loss in mice
}

\author{
Xiang $\mathrm{Li}^{1,2 \dagger}$, Lei Ning ${ }^{1,2+}$, Jianjun $\mathrm{Ma}^{1,2 \dagger}$, Ziang Xie ${ }^{1,2}$, Xiangde Zhao ${ }^{1,2}$, Gangliang Wang ${ }^{1,2}$, Xinyu Wan ${ }^{3}$,
} Pengcheng Qiu ${ }^{1,2}$, Teng Yao ${ }^{1,2}$, Haoming Wang ${ }^{4}$, Shunwu Fan ${ }^{1,2^{*}}$ and Shuanglin Wan ${ }^{1,2^{*}}$ (D)

\begin{abstract}
Background: Osteoclasts are key determinant cellular components implicated in the development and progression of disorders driven by bone damage. Herein, we studied the upshot of T007, an antagonist of peroxisome proliferatoractivated receptor-gamma (PPARY), on osteoclastogenesis using cell and animal models.

Results: The in vitro assays revealed that T007 hindered the osteoclastogenesis caused by the treatment with the receptor activator of nuclear factor-KB ligand (RANKL) through inhibiting the levels of PPARY in cells. The PPARY siRNA partially reproduced the inhibitory action of T007. The opposite findings were produced after PPARY overexpression. Furthermore, T007 prevented from bone loss in a mouse model of osteoporosis induced by ovariectomy (OVX). These findings implied that T007 is a potential efficient drug for the prophylaxis and cure of osteoclast-related disorders.
\end{abstract}

Conclusions: Taken together, our findings demonstrated that T007 impedes osteoclastogenesis and will be useful for the therapy of bone related diseases, essentially osteoporosis.

Keywords: Osteoclasts, T007, Peroxisome proliferator-activated receptor-gamma, Osteoporosis, Receptor activator of nuclear factor-KB ligand

\section{Background}

Bone homeostasis is actively maintained in equilibrium by osteoclast resorption and osteoblastogenesis [1, 2]. Excessive osteoclast activity can cause bone diseases such as osteoporosis [2]. Osteoporosis is a chronic disease characterized by decreased bone mass, abnormal microstructure of bone tissue, increased bone fragility and fracture, and has become a global public health problem [3]. At present, more than 1.02 billion people worldwide suffer from osteoporosis, and this number is expected to increase to 1.36 billion by 2030 [4]. Osteoprotegerin $(\mathrm{OPG}) /$ nuclear factor- $\mathrm{kB}$ receptor activating factor (RANK)/nuclear factor- $\mathrm{kB}$ receptor activating factor ligand (RANKL) complex is a system that plays an

\footnotetext{
* Correspondence: shunwu_fan@zju.edu.cn; wanshuanglin@zju.edu.cn ${ }^{+}$Xiang Li, Lei Ning and Jianjun Ma contributed equally to this work. 'Department of Orthopaedic Surgery, Sir Run Run Shaw Hospital, Zhejiang University School of Medicine, 3 East Qingchun Road, Hangzhou 310016, China

Full list of author information is available at the end of the article
}

important role in bone metabolism, and regulates the dynamic balance of osteoblast-mediated bone matrix synthesis and osteoclast-mediated bone resorption processes [5].

RANKL is a decisive cytokine implicated in the formation of osteoclasts, which promotes the viability and differentiation of osteoclasts [6]. The RANKL-RANK complex (RANKL receptor) leads to segregation of RANK monitoring of modulators (e.g. TRAF6 gene) and its subsequent mitogen-activated protein kinase (MAPK) activation $[7,8]$ which upregulates the expression levels of c-Fos and nuclear factor of activated T cells 1 (NFATc1) to induce osteoclastogenesis [9]. OPG is a soluble protein secreted by osteoblasts, which increases bone density and achieves its ability to inhibit bone resorption by competitively binding RANK to RANKL [10]. RANKL/OPG ratio can be used as an important indicator for bone mass and bone health [11]. Thus, signaling pathways governed by RANKL can constitute pharmacological targets for

(c) The Author(s). 2019 Open Access This article is distributed under the terms of the Creative Commons Attribution 4.0 International License (http://creativecommons.org/licenses/by/4.0/), which permits unrestricted use, distribution, and reproduction in any medium, provided you give appropriate credit to the original author(s) and the source, provide a link to the Creative Commons license, and indicate if changes were made. The Creative Commons Public Domain Dedication waiver (http://creativecommons.org/publicdomain/zero/1.0/) applies to the data made available in this article, unless otherwise stated. 
diseases involving the degradation of bone cells as supported by the effect of neutralizing RANKL antibodies, denosumab, on the cure of osteoporosis [12].

Drugs against peroxisome proliferator-activated receptor-gamma (PPAR $\gamma$ ) have been the subject of numerous studies because of their potential to treat a panoply of malignancies such as cancer. PPAR $\gamma$ is paramount involved in the formation of osteoblasts [13] since its expression level is thoroughly upregulated in osteoclastogenesis [14, 15]. PPAR $\gamma$ is acknowledged as a pharmacological target of exogenous drugs [16] because the PPARY specific inhibitors cause bone loss as a consequence of amplified bone resorption [17, 18]. Although reported in some current research works, the function of PPAR $\gamma$ in the pathophysiology osteoclasts-induced bone disorders remains unclear and has yet to be copiously elucidated.

T0070907 (T007; PubChem database SID: 53790303) has been discovered and proven as an effective and a picky competitor of PPAR [19]. Previous in vitro studies conveyed that PPAR $\gamma$ is repressed by treatment with T007 [20]. Furthermore, T007 is known to possess cancer-suppressor properties [21, 22]. For example, previous showcased that T007 modulates the expression of PPAR $\gamma$ to hinder the viability and motility of breast cancer cell [21]. In addition, T007 was conveyed as an inhibitor of cell adhesion and invasion and an inducer of anoikis in specific hepatocellular carcinoma cell lines via PPAR pathway [23]. In view of the above-mentioned regulatory features of PPAR signaling pathway in osteoclastogenesis, we hypothesize that T007 may represent a new approach to overcome bone diseases.

Thus, our goal was to inquire the properties of T007 on osteoclasts, decode the mechanisms mediated by T007 in osteoclastogenesis and test the restorative properties of T007 on bone loss in osteoporosis using a mouse model.

\section{Materials and methods}

Preparation of mouse bone marrow-derived macrophages (BMM) and osteoclast refinement

Primary BMMs were obtained by isolation from the tibia and femur bone marrow extracted from female 6-weekold C57BL/6 mice. The isolated cells were seeded in $\alpha$ MEM medium (Gibco-BRL, Gaithersburg, MD, USA) containing $30 \mathrm{ng} / \mathrm{mL}$ M-CSF (R\&D, Minneapolis, MN, USA), 10\% FBS (Gibco-BRL, Gaithersburg, MD, USA) and $1 \%$ penicillin/streptomycin (Gibco-BRL, Gaithersburg, MD, USA). The seeding was performed at $37{ }^{\circ} \mathrm{C}$ in a $5 \%$ $\mathrm{CO}_{2}$ chamber until $90 \%$ confluence. Next, the BMMs $(8 \times$ $10^{3}$ cells/well) were cultured using 96-well plates under different indicated treatment conditions with refreshment of the medium each 2 days until formation of mature osteoclasts. Subsequently, after two washes of cells using the phosphate buffered saline (PBS), cells were fixed for about
Table 1 Primer sequences for qRT-PCR analysis

\begin{tabular}{|c|c|}
\hline Primer & $5^{\prime}-3^{\prime}$ \\
\hline GAPDH-F & ACCCAGAAGACTGTGGATGG \\
\hline GAPDH-R & CACATTGGGGGTAGGAACAC \\
\hline CTSK-F & CTTCCAATACGTGCAGCAGA \\
\hline CTSK-R & TCTTCAGGGCTTTCTCGTTC \\
\hline c-Fos-F & CCAGTCAAGAGCATCAGCAA \\
\hline c-Fos-R & AAGTAGTGCAGCCCGGAGTA \\
\hline NFATC1-F & CCGTTGCTTCCAAAAATAACA \\
\hline NFATC1-R & TGTGGGATGTGAACTCGGAA \\
\hline Atp6v0d2-F & GACCCTGTGGCACTITITGTATTC \\
\hline Atp6v0d2-R & GCTTGCATTTGGGGAATCTATC \\
\hline DC-STAMP-F & AAAACCCTTGGGCTGTTCTT \\
\hline DC-STAMP-R & AATCATGGACGACTCCTTGG \\
\hline ALP-F & CCAACTCTITTGTGCCAGAGA \\
\hline ALP-R & GGCTACATTGGTGTTGAGCTIIT \\
\hline OCN-F & GAGGGCAATAAGGTAGTGAACAGA \\
\hline OCN-R & AAGCCATACTGGTTTGATAGCTCG \\
\hline Runx2-F & TTCTCCAACCCACGAATGCAC \\
\hline Runx2-R & CAGGTACGTGTGGTAGTGAGT \\
\hline Acp5-F & TCCGTGCTCGGCGATGGACCAGA \\
\hline Acp5-R & CTGGAGTGCACGATGCCAGCGACA \\
\hline OSX-F & GCTGCAAGCTCTCCATAACC \\
\hline OSX-R & GCCAGAAGCTGTGAAACCTC \\
\hline COL1a-F & TCAGACCACGGACGCCATCT \\
\hline COL1a-R & CGGCAACGATGGTGCTAAGG \\
\hline OPG-F & TGGAGAGGTAGAAAAGGCACA \\
\hline OPG-R & CAAACACACTCTTGGCACCAC \\
\hline RANKL-F & GCCAGTGGGAGATGTTAG \\
\hline RANKL-R & TTAGCTGCAAGTTTCCC \\
\hline
\end{tabular}

$20 \mathrm{~min}$ in $4 \%$ paraformaldehyde and finally stained with TRAP (Sigma-Aldrich, St. Louis, MO, USA).

\section{Measurement of T007 cytotoxicity on BMMS}

BMMs cells were culture to 96 -well plates for $24 \mathrm{~h}$ has indicated above at an inoculum of $2 \times 10^{4}$ cells/well in three biological replicates in presence of $30 \mathrm{ng} / \mathrm{mL}$ of $\mathrm{M}$ CSF. Different concentrations $(0-4.8 \mu \mathrm{M})$ of T007 were used for cell treatment and seeding was achieved for 48 $\mathrm{h}, 96 \mathrm{~h}$ in presence or absence of $30 \mathrm{ng} / \mathrm{mL}$ of M-CSF. The cytotoxic effect of T007 was assessed by the CCK-8 assay. Briefly, $10 \mu \mathrm{L}$ of CCK-8 reagent (Dojindo Molecular Technology, Kumamoto, Japan) was supplement to every well in the 96-well plate for an additional incubation time of $2 \mathrm{~h}$. The OD value was measured using the ELX800 microplate reader (Bio-Tek Instruments, Winooski, VT, USA) at a measurement wavelength of $450 \mathrm{~nm}$. 


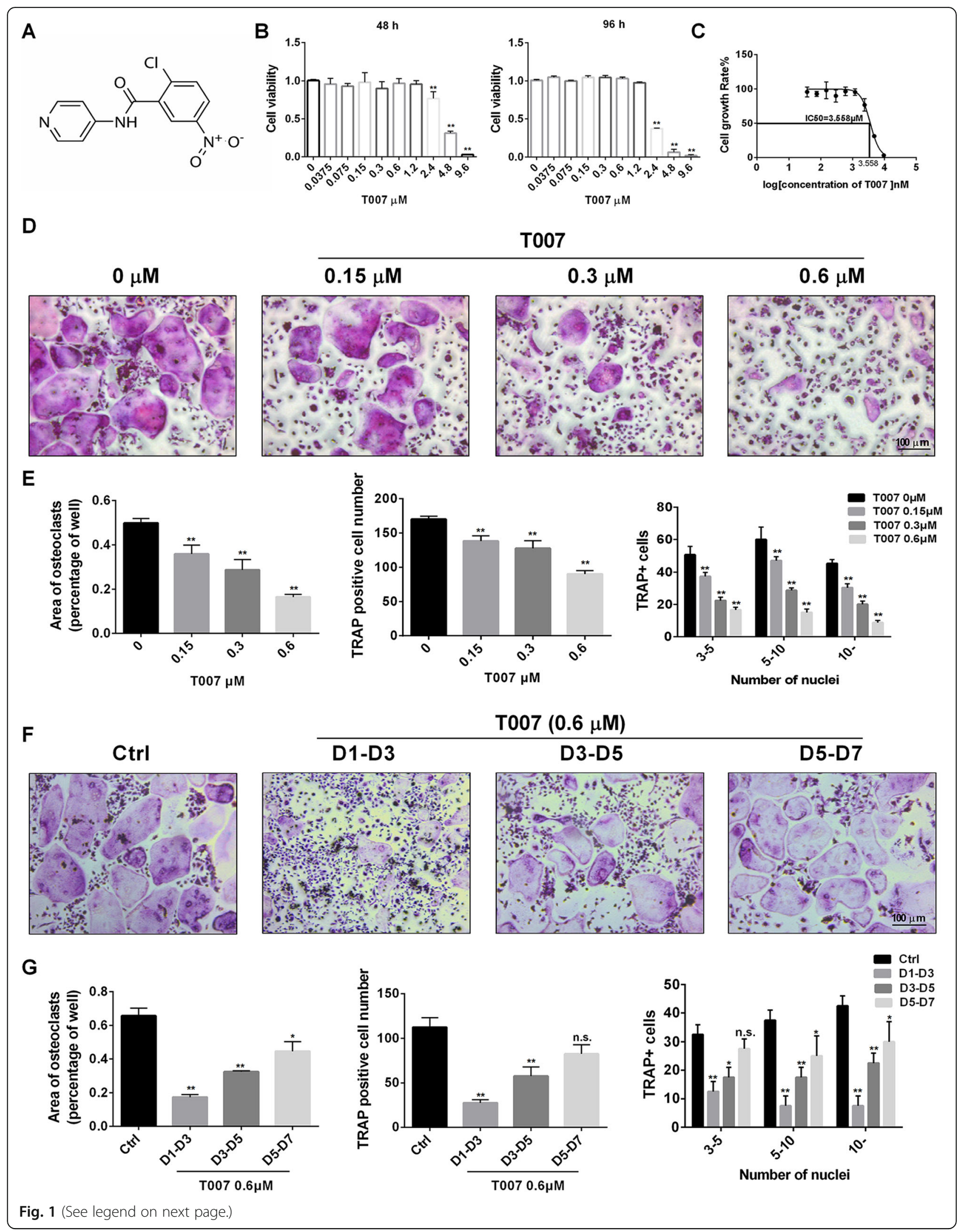


(See figure on previous page.)

Fig. 1 T007 inhibited RANKL-induced osteoclastogenesis in a time- and dose-dependent manner without cytotoxic effects in vitro. a The structure of T007. b Effects of T007 on BMMs viability by CCK8 assays at 48 and 96 h. c IC50 values obtained for the activity of T007 against BMMs. d BMMs were treated with various concentrations of T007, M-CSF $(25 \mathrm{ng} / \mathrm{mL})$ and RANKL $(50 \mathrm{ng} / \mathrm{mL})$ for 7 days. e The number, area and size of TRAP-positive multinuclear cells. f TRAP-positive BMMs following the treatment with $0.6 \mu \mathrm{M}$ T007 for the indicated days during osteoclastogenesis. g Quantification of TRAP-positive multinuclear cells, area of osteoclasts, osteoclast number and size. All experiments were performed at least three times. Scale bar, $100 \mu \mathrm{m} .{ }^{*} P<0.05$ and ${ }^{*} P<0.01$ compared with the control group

\section{Western blotting}

Each well was inoculated with $5 \times 10^{5}$ BMMs in 6-well plates and subsequently treated using various T007 (0, $0.15,0.3$, and $0.6 \mu \mathrm{M}$ ) (Sigma Aldrich, St. Louis, MO, USA) concentrations for $2 \mathrm{~h}$ as the experimental group. Untreated BMMs were used as control. Cells were activated by treatment using RANKL at a dosing of $50 \mathrm{ng} /$ $\mathrm{mL}$ for $0,1,3$, and 5 days. To explore whether T007 impacts on the expression of NFATc1, cells were incubated with a mixture containing and M-CSF $(30 \mathrm{ng} / \mathrm{mL})$ and RANKL $(50 \mathrm{ng} / \mathrm{mL})$, and added with or without $0.6 \mu \mathrm{M}$ T007 for $0,1,3$, and 5 days. The total protein was isolated from cells using the radioimmunoprecipitation assay (RIPA) lysis buffer (Sigma-Aldrich) and subsequently centrifuged for $15 \mathrm{~min}$ at $12,000 \mathrm{~g}$. Afterward, the collection of supernatants was done and followed by $10 \%$ SDSPAGE electrophoresis and transfer of aliquots to PVDF (Bio-Rad, Hercules, CA, USA) membrane. After blocking with a solution of $5 \%$ nonfat dry milk for $1 \mathrm{~h}$ at ambiant temperature, the membranes were incubated with the primary antibodies overnight at $4{ }^{\circ} \mathrm{C}$ and developed with LAS-4000 Science Imaging System (Fujiflm, Tokyo, Japan) protein. Anti-NFATc1, c-Fos, Runx2, $\beta$-catenin, RANKL, GAPDH, $\beta$-tublin and $\beta$-actin antibodies were purchased from Cell Signaling Technology (Danvers, MA, USA) and antibody against PPAR $\gamma$ and osteoprotegerin (OPG) were purchased from Abcam (Cambridge, MA, USA).

\section{RNA extraction and qRT-PCR experiments}

BMMs $\left(1 \times 10^{5}\right.$ cells/well $)$ were cultured using 6-well plates in presence of $30 \mathrm{ng} / \mathrm{mL}$ M-CSF, $50 \mathrm{ng} / \mathrm{mL}$ RANKL (R\&D, Minneapolis, MN, USA) and 0.6 $\mu \mathrm{M}$ T007. BMMs were cultured for different time points $(0,1,3$, and 5 days $)$ and total RNA was isolated with the help of the RNeasy Mini Kit (Qiagen, Valencia, CA, USA). The cDNA synthesis system was: $1 \mu \mathrm{g}$ RNA, $2 \mu \mathrm{L}$ of $5 \times$ PrimeScript $\mathrm{RT}$ Master Mix (Takara Bio, Otsu, Japan), $4 \mu \mathrm{L}$ of RNase free distilled water, total $10 \mu \mathrm{L}$. The SYBR Green QPCR Master Mix (Takara Bio) kit was used for the RT-PCR experiment. The instrument used was ABI Prism 7500 system (Applied Biosystems, Foster City, CA, USA). The reaction system was $5 \mathrm{~mL}$ SYBR Green QPCR Master Mix, $3 \mathrm{~mL}$ $\mathrm{ddH}_{2} \mathrm{O}, 1 \mathrm{~mL} \mathrm{cDNA}, 10 \mathrm{mM}$ each of forward and reverse primers, for a total of $10 \mathrm{~mL}$. The reaction was carried out at $95^{\circ} \mathrm{C}$ for $10 \mathrm{~min}$, after which each cycle was reacted at $95^{\circ} \mathrm{C}$ for $10 \mathrm{~s}, 60^{\circ} \mathrm{C}$ for $20 \mathrm{~s}, 72^{\circ} \mathrm{C}$ for $20 \mathrm{~s}, 40$ cycles and finally $72^{\circ} \mathrm{C}$ for $1 \mathrm{~min}$. The internal reference gene selected was GAPDH. The primer sequences are shown in Table 1.

\section{CCK-8 assay}

The CCK- 8 assay was the one employed for testing the cytotoxicity of T007 on BMMS. BMMs cells were plated to 96 wells at a density of $2 \times 10^{4} /$ well, three biological replicates, and $30 \mathrm{ng} / \mathrm{mL}$ of $\mathrm{M}-\mathrm{CSF}$ was added for $24 \mathrm{~h}$. The cells were incubated with diverse doses of T007 and added with $30 \mathrm{ng} / \mathrm{mL}$ of M-CSF for $48 \mathrm{~h}$ and $96 \mathrm{~h}$. Next, $10 \mu \mathrm{L}$ of CCK-8 reagent was supplemented to every well, and the 96-well plate was incubated for an additional 2 h. The OD value was measured on a microplate reader (Bio-Tek Instruments, Winooski, VT, USA) instrument using a wavelength of $450 \mathrm{~nm}$.

\section{CHIP assay}

The kit was selected from the SimpleChIP Enzymatic Chromatin IP Kit (Agarose Beads) (CST, Cambridge, MA, USA). DNAs were extracted from the treated RAW264.7 cells, and NFATc1 and genes were detected using specific primers.

\section{Cell transfection}

Control vector (pEX-3 (pGCMV/MCS/Neo) plasmid), PPAR $\gamma$ vector (recombinant plasmid containing PPAR $\gamma$, pEX-3 (pGCMV/MCS/Neo)-PPAR $\gamma$ ), control siRNA and PPAR $\gamma$ siRNA were procured from GenePharma (Shanghai, China). The transfection kit was Lipofectamine 3000 (Invitrogen, Carlsbad, CA, USA). The vectors and siRNAs sequences were separately transfected into BMMs cells which were subsequently induced into osteoclasts. The siRNA sequences were designed and synthesized by GenePharma (Shanghai, China). The relevant sequences are as follows: PPARY siRNA-1356: 5'-GACAGUGACU UGGCUAUAUTT-3'; PPARY siRNA-918: 5' -GCGAUC UUGACAGGAAAGATT-3'; negative control (NC) SiRNA: 5' -AUAUAGCCAAGUCACUGUCTT-3'.

\section{Differentiation of osteoblast stromal cells}

Mouse mesenchymal stem cells MC3T3-E1 were cultured for a period of 7 days in T007-containing a-MEM, $50 \mathrm{mg} / \mathrm{mL}-1$ ascorbic acid (Sigma-Aldrich, St. Louis, $\mathrm{MO}, \mathrm{USA}$ ) and $10 \mathrm{mM}$ b-glycerophosphate (Sigma-Aldrich, St. Louis, MO, USA) as indicated or 21 days. The 


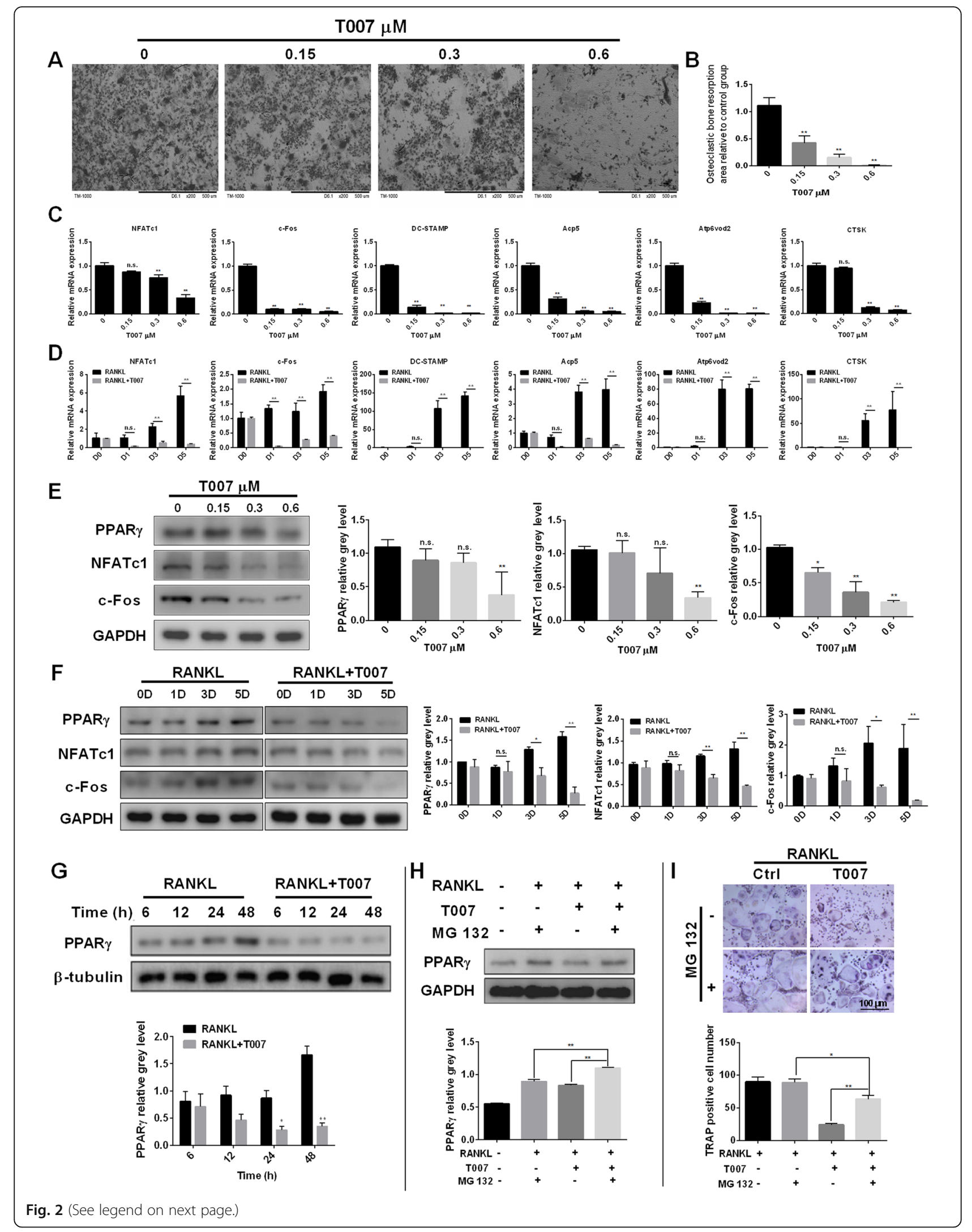


(See figure on previous page.)

Fig. 2 T007 inhibited osteoclastic bone resorption and RANKL-induced osteoclast-specific gene expression in vitro. a BMMs were seeded onto bone slices and treated the same as described in Fig. $1 \mathrm{~d}$ for 7 days and scanning electron microscope (SEM) images of bone resorption pits are shown. b Resorption pit area measurements by using Image J. c NFATc1, c-Fos, DC-STAMP, Acp5, Atp6r0d2, and CTSK expression in BMMs treated with the indicated T007 concentrations for 5 days. d NFATc1, c-Fos, DC-STAMP, Acp5, Atp6v0d2, and CTSK expression in BMMs treated with T007 $(0.6 \mu \mathrm{M})$ for $0,1,3$ or 5 days. e BMMs were treated with various concentrations of T007. Cell lysates were analyzed using western blotting. The expression of PPARY, NFATc1, and c-Fos was evaluated. f, g BMMs were treated with RANKL, with or without $0.6 \mu M$ T007 for the indicated periods. Cell lysates were analyzed using western blotting. The expression of PPARY, NFATcl, and c-Fos was evaluated. $\mathbf{h}$ The effect of T007 on the expression of PPARY in BMMs was rescued treated with $1 \mu \mathrm{M}$ of MG 132. $\mathbf{i}$ The number of TRAP-positive BMMs after treatment with RANKL, T007 $(0.6 \mu \mathrm{M})$, and MG $132(1 \mu \mathrm{M})$ for 7 days. All experiments were performed at least three times. ${ }^{*} P<0.05$ and ${ }^{* *} P<0.01$ compared with the control group

medium was revitalized every additional day. Following, the cells were stained with BCIP / NBT kit (CWBIO, Beijing, China) to detect ALP and 2\% Alizarin Red S solution ( $\mathrm{pH}$ 4.1) (Sigma-Aldrich, St. Louis, MO, USA) to visualize calcium deposition in the extracellular matrix. Mineralization was quantitated via measurements of the absorbance of the dye at $562 \mathrm{~nm}$ on the microplate reader after decolorization with ethyl pyridine chloride (Wako Pure Chemical Industries Ltd., Osaka, Japan).

\section{OVX-induced bone loss model}

The animal studies were performed in corroboration with the guidelines and protocols of the National Institutes of Health (NIH) for the Care and Use of Laboratory Animals and the guidelines for the animal treatment of Sir Run Run Shaw Hospital (Zhejiang University affiliated, Hangzhou, Zhejiang). Twenty 12-weeks old female C57BL/6 mice were sedated using $3 \mathrm{mg} / \mathrm{mL}$ of pentobarbital. Subsequently, two-sided ovariectomy (OVX) of sham operation was performed. To explore therapeutic effect of T007 on osteoporosis, these mice were arbitrarily separated into four sets $(n=5)$ : sham (blank control), vehicle control, lowdose T007 $(0.5 \mathrm{mg} / \mathrm{kg})$, and high-dose T007 $(2.5 \mathrm{mg} / \mathrm{kg})$. All mice were intraperitoneally injected with T007 each additional day for a period of 6 weeks in terms of which mice were sacrificed. Subsequently, the uterus was separated and weighed to estimate the effect of OVX. The femur of mice was fixed in $4 \%$ paraformaldehyde and accompanied by the subsequent histological and micro-CT analyses. The remaining femur samples from every mouse was kept in liquid nitrogen awaiting qRT-PCR and western blotting experiments.

\section{Micro-CT scanning}

A high-resolution micro-CT scanner (SkyScan 1072; Bruker microCT, Kontich, Belgium) was utilized for the analysis of the fixed tibias. The parameters were set as follows: isometric resolution was $9 \mathrm{~mm}, \mathrm{X}$-ray energy was $80 \mathrm{kV}$ and $80 \mathrm{~mA}$. The reconstruction program (Skyscan) was used to detect the BV/TV, BS/BV, Tb. N, Tb. Th, Tb. Sp, and porosity.

\section{Histological analysis}

The samples were examined under a high-quality microscope and photographed. The frequency of osteoblasts and TRAP-positive multinucleated osteoclasts (Oc.S/BS) and erosion surface (ES/BS) per field was examined in each sample.

\section{Statistical analysis}

The results were expressed as mean $\pm \mathrm{SD}$. Data was analyzed using Prism 7 for Windows (GraphPad Software Inc., San Diego, CA, USA). Student's t test was performed for intergroup comparisons. Comparisons between multiple groups were analyzed using one-way ANOVA or two-way ANOVA. $P<0.05$ implied a significance in the differences observed between groups.

\section{Results \\ T007 inhibited RANKL-induced osteoclastogenesis in a time- and dose-dependent manner without cytotoxic effects in vitro}

In order to check the action of T007 on RANKL-induced osteoclastogenesis in vitro, we first assessed the cytotoxicity of various T007 concentrations on bone marrow-derived macrophages (BMM) cells for $48 \mathrm{~h}$ and $96 \mathrm{~h}$. As shown in Fig. 1b, T007 concentrations greater than $2.4 \mu \mathrm{M}$ significantly inhibited cell viability. The determination of the half maximal inhibitory concentration (IC50) indicated that the IC50 of T007 is approximately $3.558 \mu \mathrm{M}$ (Fig. 1c). Thus, for subsequent experiments, we chose T007 concentrations of $0,0.15,0.3$ and $0.6 \mu \mathrm{M}$ for the dosing of BMM for 7 days. TRAP staining demonstrated that at a concentration of $0.15 \mu \mathrm{M}$, T007 exerted a considerable inhibition on the formation of osteoclasts. At a concentration of $0.6 \mu \mathrm{M}$ only a low number of osteoclasts could be identified (Fig. 1d). The number of TRAP-positive cells was decreased following the rise in T007 dose, indicating a negative correlation. In addition, the size and the number of TRAP-positive cells and that of osteoclast nuclei were remarkably decreased at the concentration of $0.6 \mu \mathrm{M}$ relatively to the control cells (Fig. 1e). To better understand the inhibitory effect of T007 during osteoclast differentiation, we treated RANKLinduced osteoclasts with a T007 concentration of $0.6 \mu \mathrm{M}$ at different time intervals during osteoclast formation. 


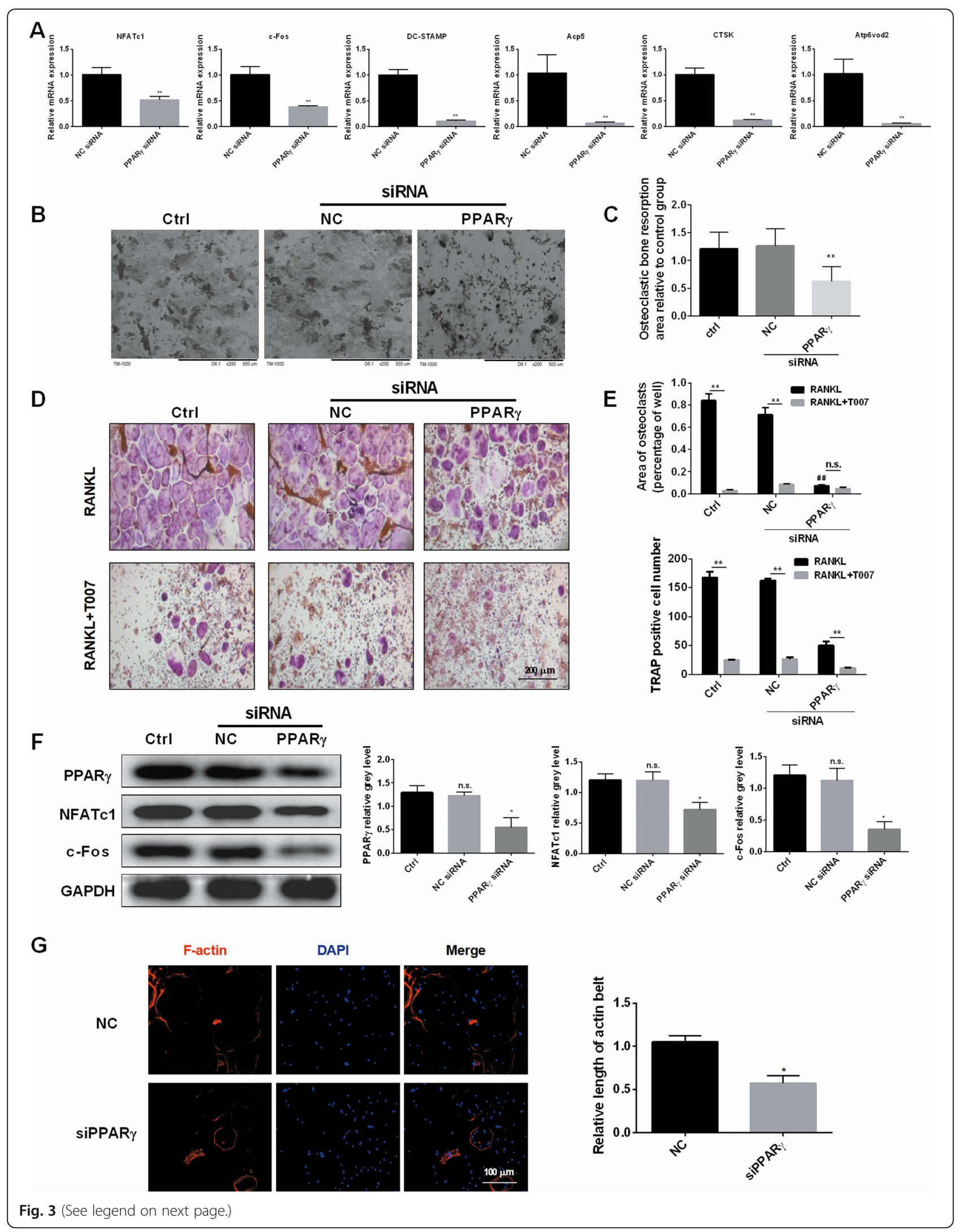


(See figure on previous page.)

Fig. 3 Loss of function by knocking down PPARy impaired RANKL-induced osteoclast-specific gene expression and inhibited osteoclast differentiation in vitro. a Expression of the osteoclast-specific genes NFATc1, c-Fos, DC-STAMP, Acp5, Atp6v0d2, CTSK in RAW264.7 cells following the transfection with PPARY siRNA. Negative siRNA was used as a control. b, $\mathbf{c}$ The bone resorption pits of BMMs after the transfection with siRNA were detected using scanning electron microscope (SEM) images, and the resorption pit area measurements by using Image J. Untreated cells were used as a control. $\mathbf{d}$, e The number and area of TRAP-positive BMMs after the transfection with siRNA and the treatment with T007 (0.6 $\mu \mathrm{M})$. Untreated cells were used as a control. f BMMs were transfected with siRNA, untreated cells were used as a control. Cell lysates were analyzed using western blotting. The expression of PPARY, NFATc1 and c-Fos was evaluated. $\mathbf{g}$ The effect of siPPARy on the formation of F-actin ring. All experiments were performed at least three times. ${ }^{*} P<0.05$ and ${ }^{* *} P<0.01$ compared with the control group. \# \# $P<0.01$ compared with the RANKL group

Figure 1f and g depicted that osteoclast formation was significantly reduced after the addition of T007 at the primary phase of differentiation (days 1 to 3). Moreover, the addition of T007 at the intermediate stage of osteoclast differentiation (days 3 to 5 ) was also followed by a notable lessening in the amount of mature osteoclasts compared to the control group, but the degree of reduction was lower than that observed at the beginning of the differentiation. The addition of T007 at the advanced phase of osteoclastogenesis (days 5-7) was not followed by a significant decline in the amount of osteoclasts; however, small osteoclasts could be observed (Fig. 1f, g). Therefore, these observations indicate that T007 primarily hinders the osteoclastogenesis at the initial steps of osteoclast differentiation.

T007 inhibited osteoclastic bone resorption and RANKLinduced osteoclast-specific gene expression in vitro

For a better insight into the effect of T007 on the bone resorption ability of osteoclasts, we added T007 in the medium after placing BMMs on 96-well plate bovine bone slices. The increase in T007 concentration was followed by significantly decreased area of bone resorption, especially at a concentration of $0.6 \mu \mathrm{M}$ (Fig. 2a, b). To better figure out the hindrance of T007 on osteoclastogenesis, we measured the transcription levels of osteoclast-related genes such as DC-STAMP, CTSK, c-Fos and NFATc1. The expression of these genes was pointedly subdued by the adjunction of T007 compared with the control (Fig. 2c). Without treatment with T007, induction with RANKL promoted the expression of c-Fos, NFATc1, Acp5, DCSTAMP, CTSK and Atp6v0d2 genes. On the contrary, the concomitant application of T007 and RANKL significantly downregulated these six genes (Fig. 2d). Western blotting also indicated that the addition of different concentrations of T007 repressed the levels of PPAR $\gamma$, NFATc1 and c-Fos at protein level. Specifically, 0.6 $\mu \mathrm{M}$ T007 significantly and strongly downgraded the expression of the PPAR NFATc1 and c-Fos (Fig. 2e). Therefore, we used $0.6 \mu \mathrm{M}$ T007 for additional western blotting experiments. The treatment of BMMs with RANKL favored the expression of PPAR- $\gamma$, NFATc1 and c-Fos proteins in a timedependent manner. The simultaneous treatment with both RANKL and 0.6 $\mu \mathrm{M}$ T007 inhibited PPAR $\gamma$, NFATc1, and c-Fos (Fig. 2f, g). Moreover, we further found that
$1 \mu \mathrm{M}$ of MG 132, a protease inhibitor, significantly increased the expression of PPAR $\gamma$ (Fig. 2h) and the number of TRAP-positive cells (Fig. 2i), suggesting that MG 132 can attenuate the inhibitory effect of T007 on osteoclasts. Concurrently, we also performed an immunofluorescence analysis of PPAR $\gamma$ and c-Fos and found that, relatively to the control group, PPAR $\gamma$ and c-Fos protein expression levels were significantly reduced after the addition of $0.6 \mu \mathrm{M} \mathrm{T} 007$, consistent with the above results (Additional file 1: Figure S1A). To investigate whether T007 causes apoptosis of osteoclasts, we performed a flow cytometry experiment and found that when T007 was added, the number of viable cells in osteoclasts was drastically reduced and that the number of apoptotic and dead cells was significantly increased (Additional file 1: Figure S1B). To uncover the mutual interaction of proteins and genes, we performed CHIP experiments and found that T007 could block the binding of RANKL to the c-Fos gene. Thus, T007 downregulates c-Fos by blocking the interaction of RANKL to the cFos gene, thereby inhibiting RANKL-induced osteoclastogenesis in vitro (Additional file 1: Figure S1C). The formation of F-actin ring was also markedly decreased by $0.6 \mu \mathrm{M}$ T007 compared with the control group (Additional file 1: Fig. S1D, E). Furthermore, PPARy accumulated in close proximity to $\mathrm{F}$-actin ring in mature osteoclast (Additional file 1: Figure S1F). It was reasonable to anticipate that PPAR $\gamma$ was implicated in osteoclastic bone resorption because extensive reports argued that F-actin is vital for osteoclast function [24]. Additionally, IP assay also verified that T007 can reduce the expression of PPAR $\gamma$ induced by RANKL (Additional file 1: Fig. S1G).

\section{Loss of function by knocking down PPARY impaired RANKL-induced osteoclast-specific gene expression and inhibited osteoclast differentiation in vitro}

Next, we transfected RAW264.7 cells with PPAR- $\gamma$ siRNA to study the effects of c-Fos, NFATc1, Acp5, DC-STAMP, CTSK, Atp6v0d2 gene expression. The levels of these osteoclast-specific genes were significantly downgraded when contrasted with the control group (Fig. 3a). This indicated that PPAR $\gamma$ promotes the expression of osteoclast-specific genes such as c-Fos, NFATc1, and 


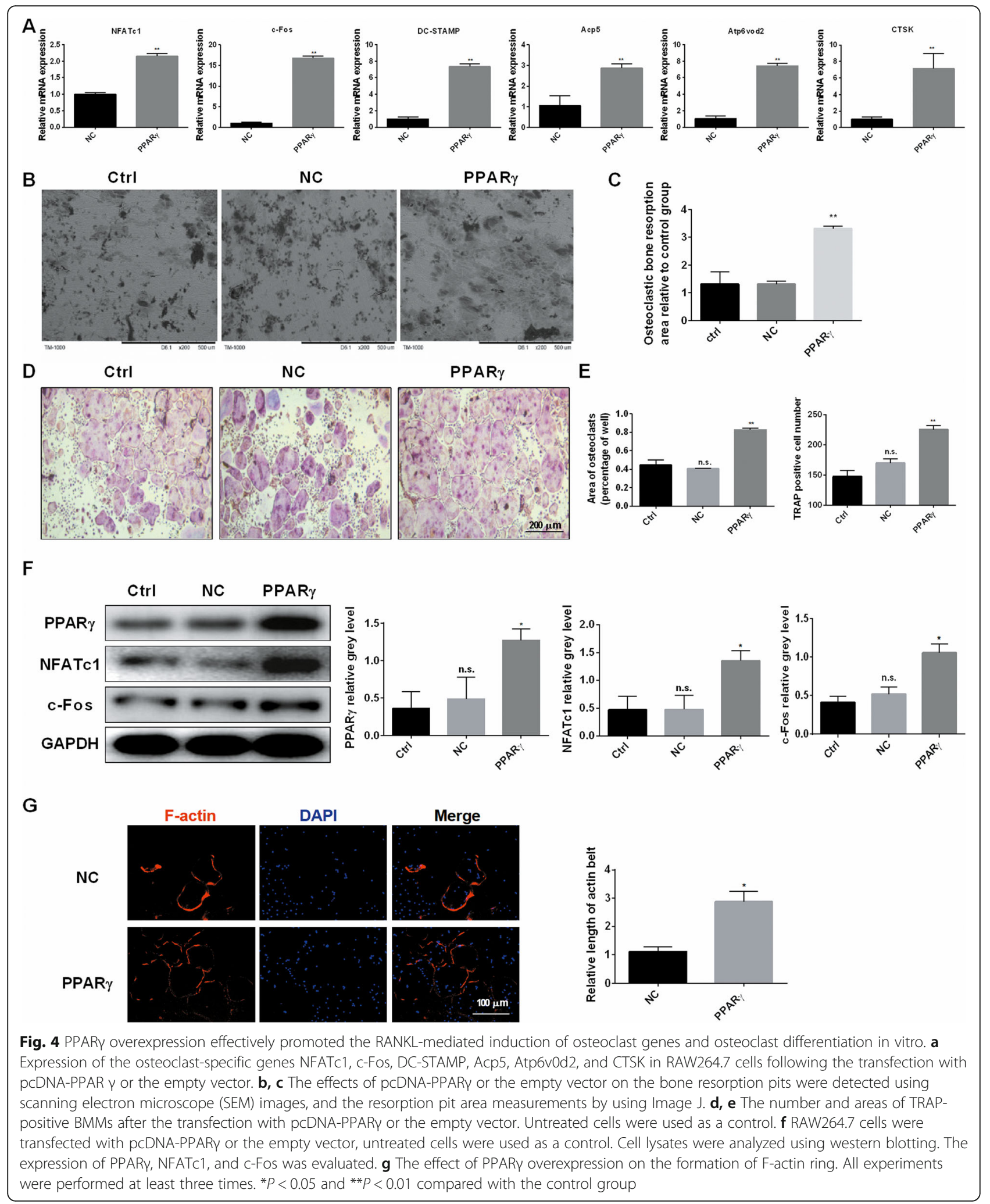

Acp5, which promotes the osteoclastogenesis. For a further understanding on the action of PPAR- $\gamma$ siRNA on the bone resorption ability of osteoclasts, we detected the bone resorption pits of BMMs after the transfection with PPAR$\gamma$ siRNA. PPAR- $\gamma$ siRNA significantly declined the area of bone resorption compared with the control group (Fig. 3b, 


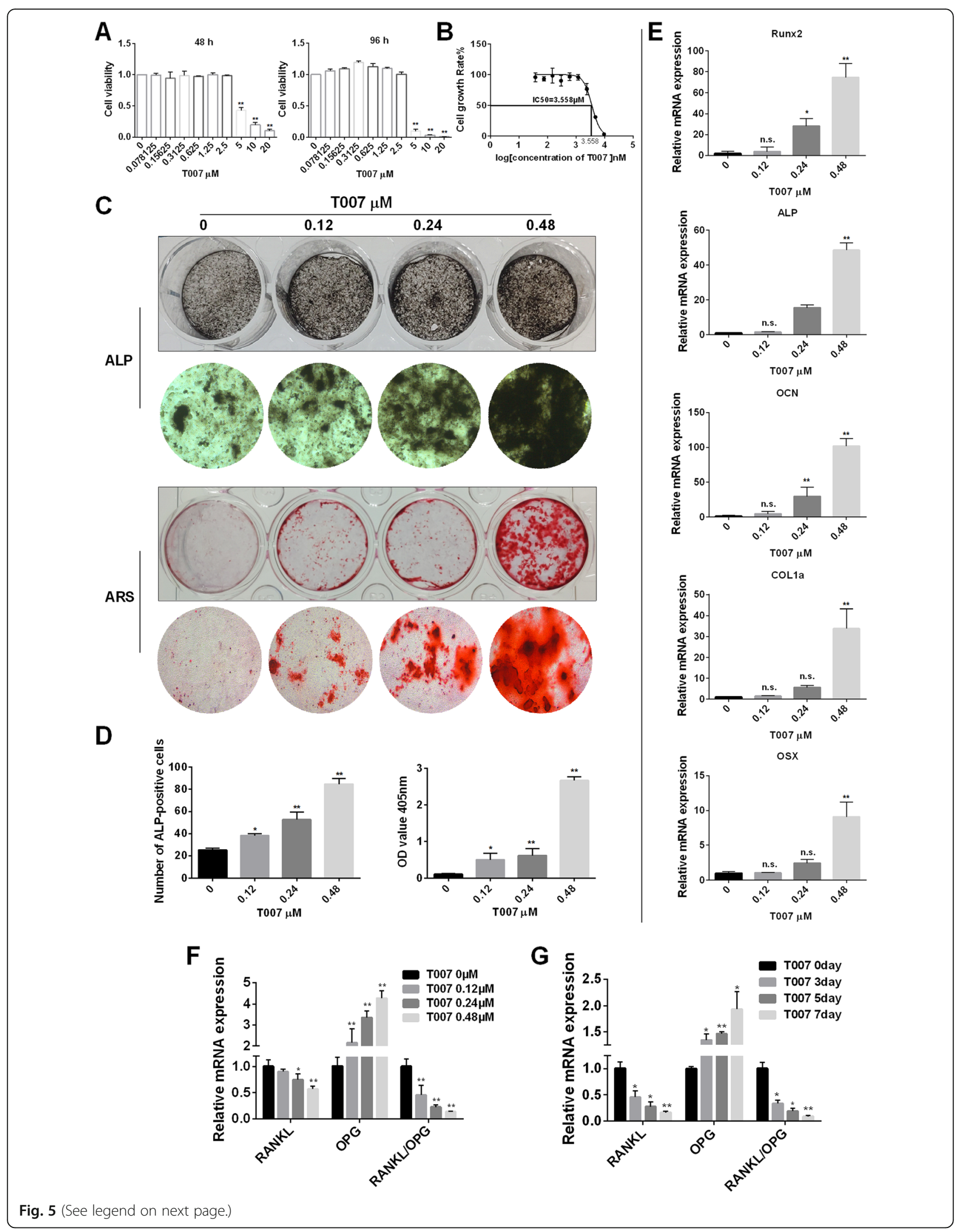


(See figure on previous page.)

Fig. 5 T007 effected on osteoblastogenesis and osteoblast-specific gene expression. a IC50 values obtained for the activity of T007 against MC3T3-E1 cells. b Effect of T007 on MC3T3-E1 on cell viability by CCK8 assays at 48 and 96 h. c ALP expression in osteoblasts and treated with various concentrations of T007 for 7 days. Mineralized extracellular matrix was detected using Alizarin Red S staining for 21 days. $\mathbf{d}$ The number of ALP-positive cells and the OD values obtained for mineralized matrix solutions following the treatment with T007. e Expression of the osteoblastspecific genes Runx2, ALP, OCN, COL1a, and OSX in MC3T3-E1 cells treated with various concentrations of T007 for 7 days. f, $\mathbf{g}$ The expression levels of RANKL, OPG, and RANKL/OPG in MC3T3-E1 cells treated with various concentrations of T007 for 0, 1, 3 or 5 days. The results were normalized to the expression levels of GAPDH. All experiments were performed at least three times. ${ }^{*} P<0.05$ and ${ }^{* *} P<0.01$ compared with the control group

c). TRAP staining displayed that, in the case of RANKL alone, the area of TRAP-positive cells and osteoclasts did not change significantly in the blank control and the negative control, but significantly decreased in the experimental group compared to the former two groups. Additionally, the concurrent treatment with RANKL and T007 decreased the area of TRAP stained cells and osteoclasts in the three groups comparatively to the case of RANKL only treatment (Fig. 3d, e). Similarly, western blot experiments showed that the expressions of PPAR $\gamma$, NFATc1, and cFos were insignificantly different between the blank group and the negative control group, but significantly decreased in the experimental group (Fig. 3f). Moreover, siPPAR considerably repressed the expression of F-actin compared to the control group (Fig. 3g), which was similar to the effect of T007.

\section{PPARY overexpression effectively promoted the RANKL- mediated induction of osteoclast genes and osteoclast differentiation in vitro}

To increase persuasiveness, we performed a reverse validation experiment that overexpressed PPAR $\gamma$ in RAW264.7 cells. As a result, as shown in Fig. 4a, the amount of osteoclast-specific gene expression was considerably upgraded in the experimental group transfected with pcDNA-PPAR $\gamma$ in contrast with the control group transfected with empty vector. Moreover, compared to the control group, PPARY overexpression significantly increased bone resorption area (Fig. 4b, c). TRAP staining experiments showed that the frequency of TRAP-positive cells or osteoclasts in the experimental group was significantly higher compared with the blank and control groups, and there was no obvious discrepancy between the blank and the control groups (Fig. 4d, e). In western blotting, we revealed that PPAR $\gamma$, NFATc1, and c-Fos protein synthesis were significantly upregulated in the experimental group (Fig. 4f). Furthermore, PPARy overexpression significantly promoted the expression of F-actin relatively to the control group (Fig. 4g).

\section{T007 effected on osteoblastogenesis and osteoblast- specific gene expression}

To explore the effects of T007 on osteoblast formation and specific gene expression in osteoblasts, we performed the following experiments. First, we treated MC3T3-E1 cells with various doses of T007. When the concentration was less than $3 \mu \mathrm{M}$, T007 did not affect osteoblasts. At concentrations higher than $3 \mu \mathrm{M}$, the cytotoxicity increased with the increase of T007 concentration with the IC50 value of $3.705 \mu \mathrm{M}$ (Fig. 5a, b). We then chose the T007 concentrations of $0.12 \mu \mathrm{M}, 0.24 \mu \mathrm{M}$, and $0.48 \mu \mathrm{M}$ to treat osteoblasts, and stained the treated osteoblasts with ALP and ARS. As a result, T007-treated osteoblasts had a deep staining effect and the darkest color at $0.48 \mu \mathrm{M}$, indicating that T007 can promote the formation of osteoblasts in vitro (Fig. 5c, d). The treated osteoblasts were tested by qRT-PCR to gage the expression changes of osteoblast-specific markers. The expression of osteoblast-specific genes was significantly increased by $0.48 \mu \mathrm{M}$ T007, indicating that T007 upregulated the expression levels of osteoblast-specific genes (Fig. 5e). Furthermore, we detected the effect of T007 on the expression levels of RANKL and OPG, and the results showed that T007 inhibited the expression of RANKL, promoted the expression of OPG, and decreased the ratio of RANKL/OPG in a dose- and time-dependent manner (Fig. 5f, g).

Western blotting was also performed to detect the expression of relevant proteins. It was found that the levels of PPAR $\gamma$ and RANKL and the RANKL/OPG ratio in T007-treated osteoblasts were significantly decreased, while Runx2, $\beta$-catenin and OPG were considerably upregulated (Fig. 6a-d). This implied that T007 can downregulated osteoclasts-related proteins and upregulated osteoblasts related-proteins. Next, the osteoblasts were treated with OB and PPAR $\gamma$, Runx2, $\beta$-catenin, RANKL, and OPG were tested for expression levels. Compared with the control group, OB induced Runx2, $\beta$-catenin and OPG expressions but inhibited the expression of PPAR $\gamma$ and RANKL and the RANKL/OPG ratio. When osteoblasts were concurrently treated with $\mathrm{OB}$ and $0.48 \mu \mathrm{M}$ T007, the promoting effect was more pronounced and there was a remarkable difference compared to OB treatment alone (Fig. $6 \mathrm{e}-\mathrm{l})$. At the same time, we performed immunofluorescence analysis of PPAR $\gamma$ and Runx2, and found that compared with the control group, the expression of PPAR $\gamma$ protein in osteoblasts was significantly decreased and Runx 2 protein expression was increased after adding $0.48 \mu \mathrm{M}$ of T007 (Fig. $6 \mathrm{~m}$ ). Furthermore, we also found that $1 \mu \mathrm{M}$ of $\mathrm{MG}$ 132 significantly upregulated the expression of PPARY (Fig. 


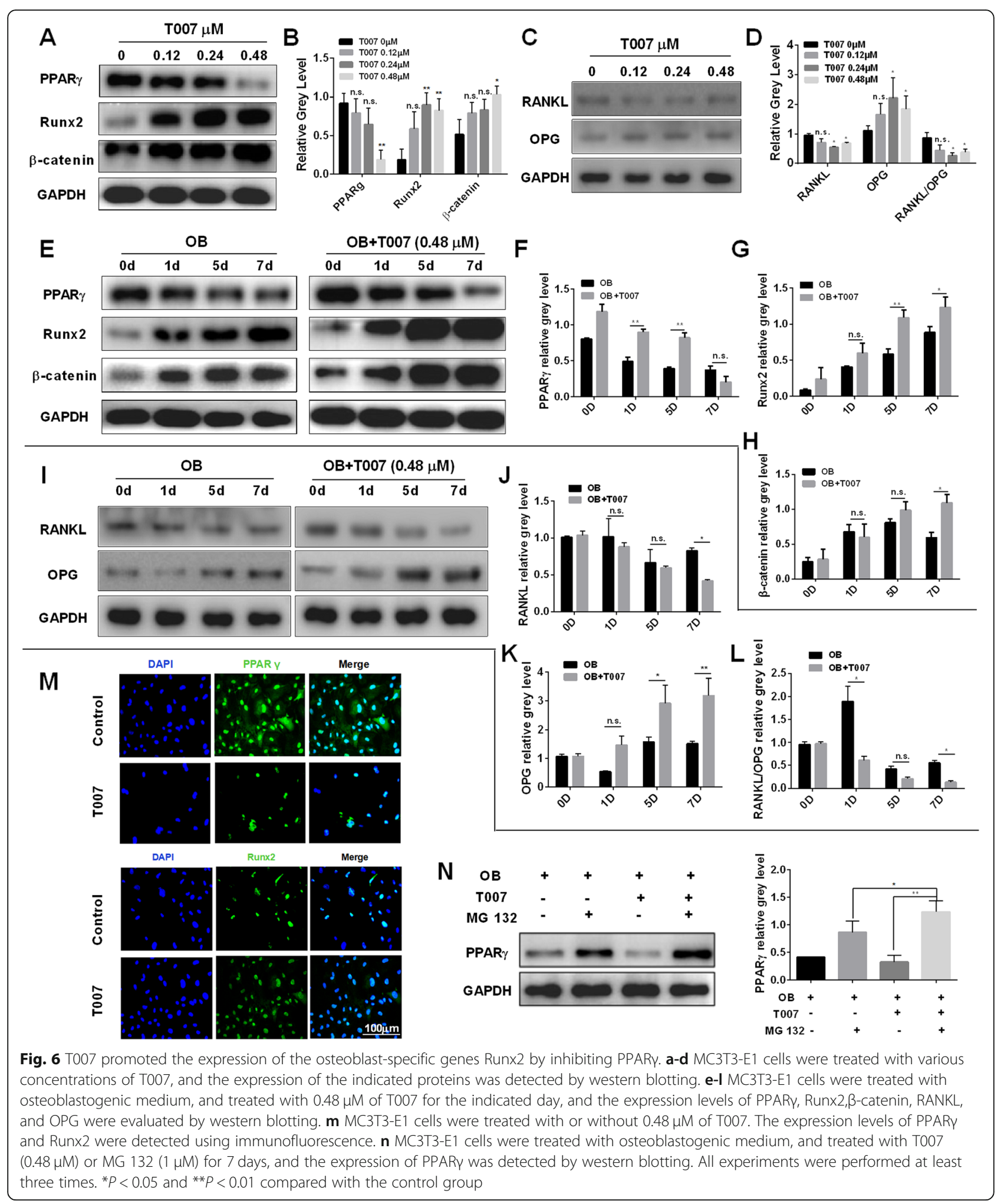




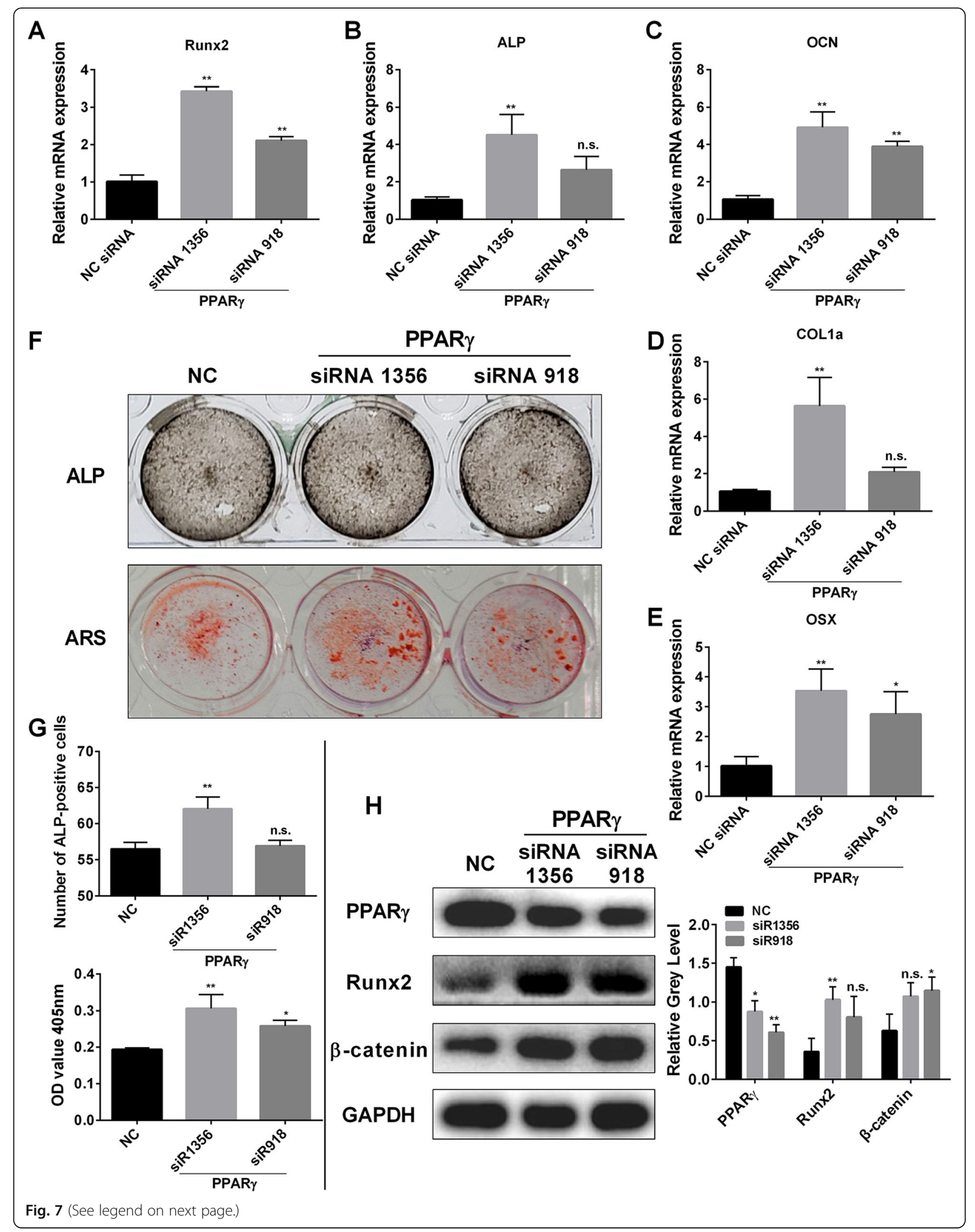


(See figure on previous page.)

Fig. 7 Knock-down of PPARy promotes osteoblastogenesis and the expression of osteoblast-specific gene expression in vitro. a-e Expression of the osteoblast-specific genes Runx2, OCN, OSX, ALP, COL1a, and OSX in osteoblasts following the transfection with two kinds of siRNA or the negative control. $\mathbf{f}$ ALP expression in osteoblasts cultured in the osteogenic medium and mineralized extracellular matrix was detected using Alizarin Red S staining treated after transfection with two kinds of siRNA or the negative control for 7 days and 21 days. $\mathbf{g}$ The number of ALPpositive cells and the OD values obtained for mineralized matrix solutions following transfected with siRNA or the negative control. $\mathbf{h}$ Osteoblasts were transfected with two kinds of siRNA or the negative control. Cell lysates were analyzed using western blotting. The expression of PPARY,

Run $\times 2$, and $\beta$-catenin was evaluated. All experiments were performed at least three times. ${ }^{*} P<0.05$ and ${ }^{* *} P<0.01$ compared with the control group

6n), indicating that MG 132 can attenuate the promotion effect of T007 on osteoblasts.

\section{Knocking down PPARy promotes osteoblastogenesis and the expression of osteoblast-specific gene expression in vitro}

Osteoblasts were transfected with two siRNAs (siRNA1356, siRNA918) and the empty vector, respectively. The transfection with siRNA1356 and SiRNA918 inhibited PPAR $\gamma$ expression. The results showed that Runx2, OCN, ALP, COL1a and OSX genes were significantly upregulated in the two groups (Fig. 7a-e). ALP and ARS staining indicated that siRNA silencing led to darker-stained compared to the negative control group, indicating that osteoblast differentiation was promoted (Fig. 7f). The statistical results were consistent with these observations (Fig. 7g). Western blotting was also used to gage PPAR $\gamma, \operatorname{Runx} 2$, and $\beta$-catenin a protein expression levels. The results are shown in Fig. $7 \mathrm{~h}$ and indicated that in the experimental group, the expression level of PPAR- $\gamma$ protein was downregulated, while the synthesis of Runx 2 and $\beta$-catenin increased was increased.

On the contrary, the overexpression of PPAR $\gamma$ revealed a significant decrease in the expression levels of osteoblast-specific genes Runx2, OCN, ALP, COL1a and OSX (Fig. 8a-e). The ALP, ARS staining, osteoblast staining of PPAR $\gamma$ overexpression was lighter than the negative control group. The number of ALP stained cells and the OD at $405 \mathrm{~nm}$ decreased significantly (Fig. 8f, g). Western blotting assay showed that PPAR $\gamma, \beta$-catenin and Runx2 were upregulated (Fig. 8h).

\section{T007 promotes BMSCs differentiation into osteoblasts} in vitro and expression of the osteoblast-specific genes To explore whether T007 affects the osteoblastogenesis of BMSCs in vitro, we added different concentrations of T007 to the osteogenic medium of BMSCs. The addition of $0.48 \mu \mathrm{M}$ T007 led to the deepest ALP and ARS stained cells (Fig. 9a). The statistical results were coherent with these observations (Fig. 9b). Furthermore, the Runx2, OCN and ALP mRNA levels were also significantly increased while the COL1a mRNA level was increased but showed no significant difference (Fig. 9c). Western blotting indicated that, the addition of $0.48 \mu \mathrm{M}$
T007 showed a significant downregulation of PPAR- $\gamma$ protein and a significant increase in Runx2 expression (Fig. 9d, e). After transfection of BMSCs with pcDNA-PPARy, ALP and ARS staining displayed that the amount of osteoblasts in the experimental group were lower compared to the control group (Fig. 9f-h). Western blotting indicated an increase in PPAR $\gamma$ protein expression and a downregulation in Runx2 expression (Fig. 9i, j). The expression levels of osteoblast-specific genes were decreased (Fig. 9k). On the contrary, the transfection of BMSCs with siR918, siR1356 led to the deepest ALP and ARS stained cells (Fig. 9l, $\mathrm{m}$ ). In addition, the transfection of BMSCs with siR918 and siR1356 increased the number of osteoblasts with decreased PPAR $\gamma$ protein expression (Fig. 9n, o). The Runx2 protein expression was, on the contrary, increased (Fig. 9n, o). The levels of osteoblast-specific genes were significantly increased (Fig. 9p-s). Additionally, the treatment of BMSCs with $0.48 \mu \mathrm{M}$ of T007 significantly inhibited the expression level of PPAR $\gamma$ in a time-dependent manner (Fig. 9t). T007 can reduce PPAR $\gamma$ expression in BMSCs, and this inhibitory effect can be attenuated by MG 132 (Fig. 9u).

\section{T007 prevents from OVX-induced bone loss}

To validate the potential therapeutic effect of T007 on osteoporosis, we further examined T007 action in a mouse model of osteoporosis. Compared with the sham group, vehicle (OVX) treatment significantly increased the body weight and decreased the uterine weight of mice, indicating that the osteoporosis model was successfully constructed (Fig. 10a b). The qRT-PCR experiments indicated that the osteoclastogenesis related genes were promoted in animals bearing osteoporosis comparatively to the healthy animals. The treatment of mice with T007 decreased the levels of these osteoclastogenesis genes in a dose-dependent fashion compared to the osteoporosis animals administered with the vehicle (Fig. 10c). Moreover, T007 treatment significantly increased the mRNA and protein expression levels of OPG in OVX-induced bone loss models, while inhibiting RANKL expression and the ratio of RANKL/OPG (Fig. 10d-f). This implied that T007 prevents from OVX-induced bone loss. Micro-CT analysis indicated an obvious bone loss in the femur of osteoporosis animals treated with vehicle. Bone quality indices 


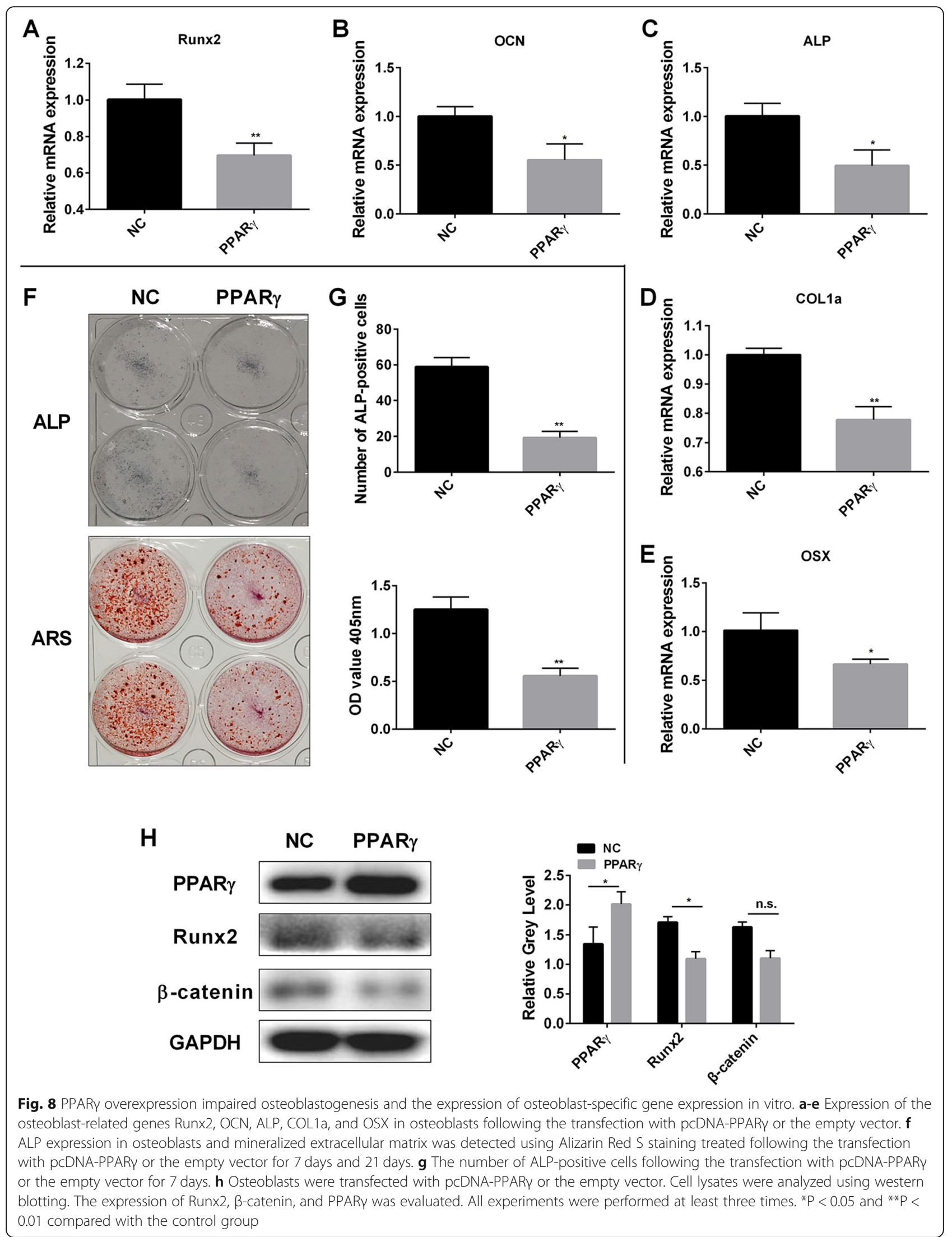




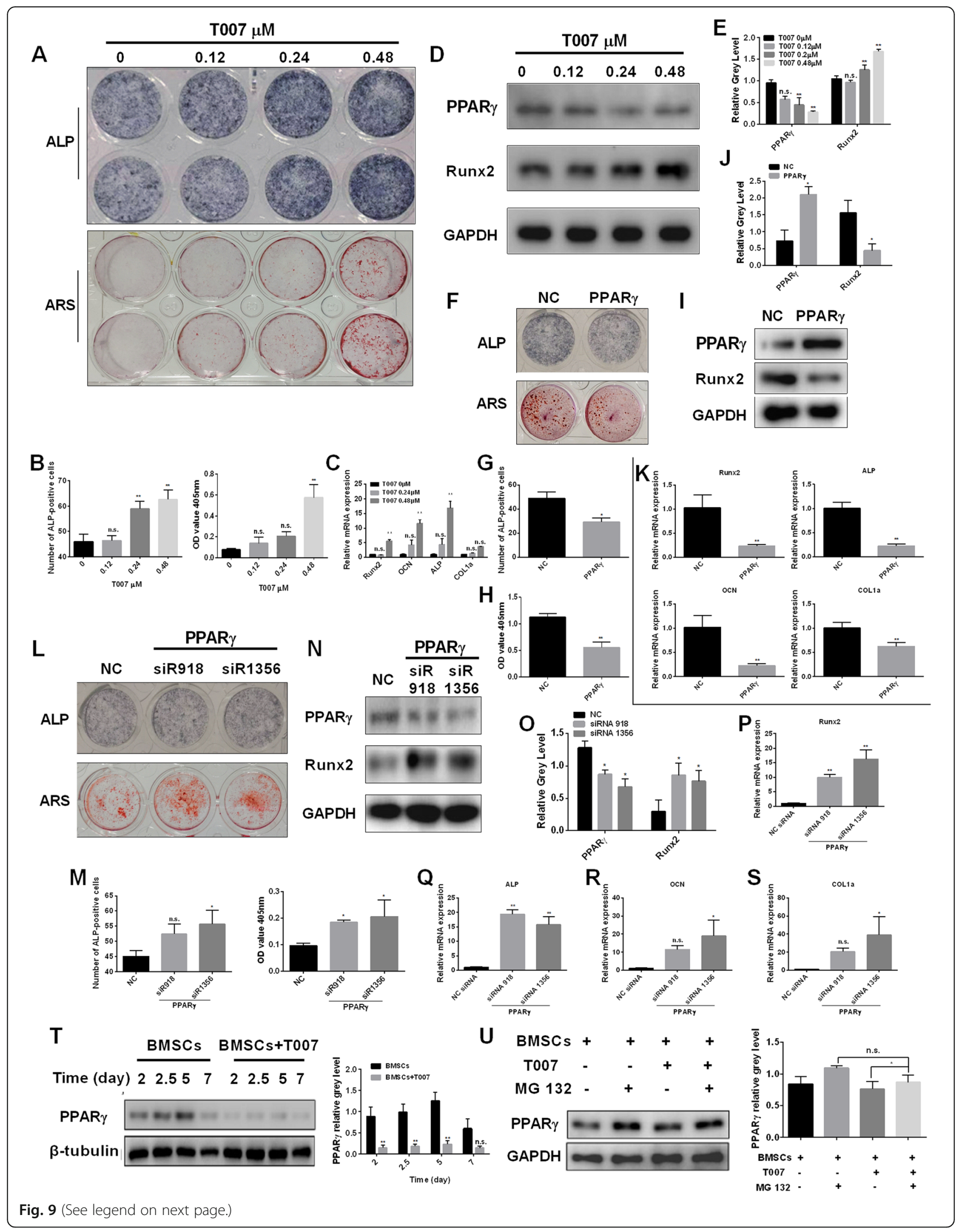


(See figure on previous page.)

Fig. 9 T007 promotes BMSCS differentiation into osteoblasts in vitro and expression of the osteoblast-specific genes. a ALP expression in BMSCs cultured in the osteogenic medium and treated with various concentrations of T007 for 7 days. Mineralized extracellular matrix was detected using Alizarin Red S staining for 21 days. b Expression of the osteoblast-specific genes Runx2, OCN, ALP, and COL1a in BMSCs with T007-treated maintained in osteogenic medium for 7 days. $\mathbf{c}$ The number of ALP-positive BMSCs and the OD values obtained for mineralized matrix solutions following the treatment with T007. d, e BMSCs were treated with various concentrations of T007, and the expression of the indicated proteins was detected by western blotting. f ALP expression in BMSCs and mineralized extracellular matrix was detected using Alizarin Red $\mathbf{S}$ staining treated following the transfection with pcDNA-PPARy or the empty vector for 7 days and 21 days. $\mathbf{g}, \mathbf{h}$ The number of ALP-positive cells following the transfection with pcDNA-PPARY or the empty vector for 7 days. $\mathbf{i}, \mathbf{j}$ BMSCs were transfected with pcDNA-PPARy or the empty vector. Cell lysates were analyzed using western blotting. The expression of Runx2, PPARy was evaluated. $\mathbf{k}$ Expression of the osteoblast-related genes Runx2, OCN, ALP, and COL1a in BMSCs following the transfection with PCDNA-PPARY or the empty vector. I ALP expression in BMSCs cultured in the osteogenic medium and mineralized extracellular matrix was detected using Alizarin Red S staining treated after transfected with two kinds of siRNA or the negative control for 7 days and 21 days. $\mathbf{m}$ The number of ALP-positive cells and the OD values obtained for mineralized matrix solutions following transfected with siRNA or the negative control. $\mathbf{n}$, o BMSCs were transfected with two kinds of siRNA or the negative control. Cell lysates were analyzed using western blotting. The expression of PPARy, Runx2 was evaluated. p-s The expression levels of the osteoblastspecific genes (Runx2, OCN, OSX, ALP, and COL1a) in BMSCs following the transfection with two kinds of siRNA or the negative control. $\mathbf{t}$ BMSCs were treated with or without $0.48 \mu \mathrm{M}$ of T007 for the indicated periods. Cell lysates were analyzed using western blotting. The expression of PPARy was evaluated. u BMSCs were treated with T007 $(0.48 \mu \mathrm{M})$ or MG $132(1 \mu \mathrm{M})$ for 7 days, and the expression of PPARy was detected by western blotting. All experiments were performed at least three times. ${ }^{*} P<0.05$ and ${ }^{* *} P<0.01$ compared with the control group

including such as BV/TV, Tb. N, and Tb. Th values were decreased while Tb. Sp and BS/BV values were significantly upgraded (Fig. 10g, h). Hematoxylin and eosin (H\&E) histopathological examination revealed reduction in the number and the thickness of trabecular (Fig. 10i). Also, TRAP staining indicated that the number of multinucleated osteoclasts was obviously enlarged in the vehicle-treated animals but were decreased in the T007treated groups (Fig. 10j). Additionally, T007 significantly reduced the osteoclast surface/bone surface area (OcS/BS) and TRAP positive cell number (Fig. 10k, l), suggesting that T007 can repress osteoclast formation and osteoclastic bone loss in vivo. The von Kossa staining results showed that the trabecular bone density and the ratio of mineralized area to bone surface area (MS/BS (\%)) were declined in the vehicle-treated group, while T007 treatment could improve these results (Fig. 10m, n). Furthermore, the calcein dual fluorescent labeling revealed that compared with the vehicle group, T007 remarkably increased the MAR of the femur (Fig. 10o, p).

\section{Discussion}

The occurrence of osteoporosis is a complex process. Previous studies have confirmed that multiple stimuli and numerous regulatory factors involved in the pathogenesis of osteoporosis interact with each other to ultimately lead to the occurrence of osteoporosis subsequently to their combined regulatory action $[25,26]$. Although many therapies for osteoclasts such as estrogen-replacement therapy and bisphosphonates have been performed [27], further alternative therapies are needed due to the multiple side effects of existing therapies. Recent studies have shown that bisphosphonates have serious side effects of mandibular necrosis [28]. Here, we explored the effect of PPAR $\gamma$ antagonist T007 on the differentiation and resorption of multinucleated osteoclasts. In this research, we demonstrated that T007 can prevent RANKL-induced osteoclastogenesis through inhibiting PPAR $\gamma$ and promoting OPG to subsequently induce the osteoblast differentiation in vitro. Furthermore, our results also showed that T007 can prevent OVX-induced bone loss in vivo. Therefore, our study found that T007 is a candidate drug for treating osteoporosis, and our results help to enlighten the mechanism underlying the effect of T007, which is beneficial for further research and application.

The OPG/RANKL/RANK complex is a regulatory system closely related to the occurrence of osteoporosis and can affect the function of osteoclasts; especially, the change of OPG/RANKL ratio can directly affect the proliferation and differentiation of osteoclasts, thereby affecting bone metabolism $[29,30]$. OPG competes with RANK for binding to RANKL, thereby blocking the binding of RANKL to RANK on the precursor cell membrane, delaying the differentiation of precursor osteoclasts, and reducing bone resorption. The change of OPG/RANKL ratio is the most direct indicator of the activation and proliferation of osteoclasts, which decrease will promote the proliferation and differentiation of osteoclasts, leading to the occurrence of osteoporosis [31]. Studies have found that certain Chinese medicines such as Yunnan Baiyao can upregulate OPG expression and downregulate RANKL expression in osteoblasts, which reduces the formation of osteoclasts and inhibits the activation of osteoclasts [32]. To investigate whether T007 indirectly control osteoclast differentiation, we examined the expression levels of RANKL and OPG during osteoblast differentiation, and analyzed the relative ratio of RANKL/OPG. We found that T007, an antagonism of PPARy, significantly increased OPG expression and declined RANKL expression and RANKL/OPG ratio. Lee, Lee [33] found that rosiglitazone, an agonist of PPAR $\gamma$, 


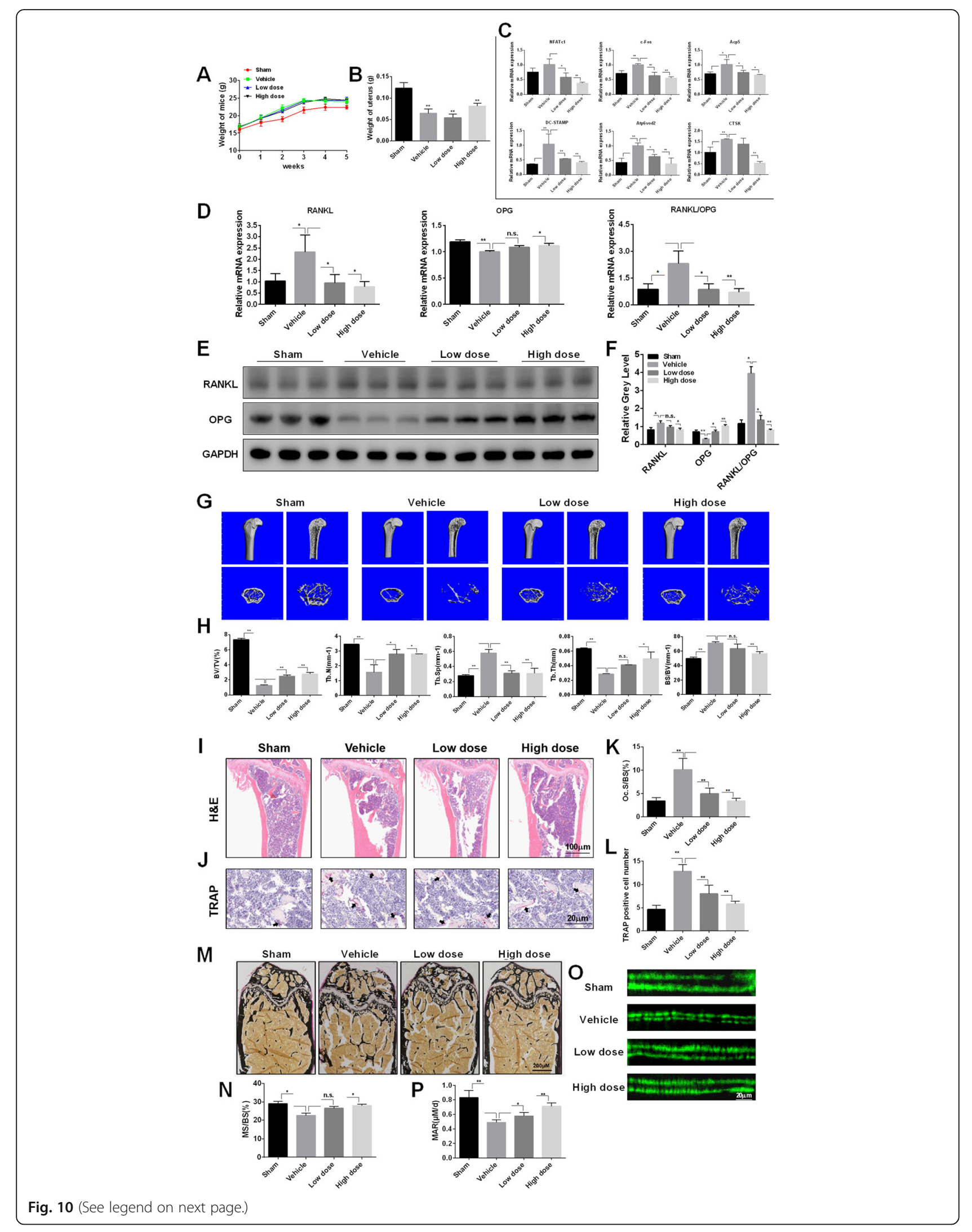


(See figure on previous page.)

Fig. 10 T007 prevention of OVX-induced bone loss in vivo. Verify whether the osteoporosis mouse model induced by OVX was successfully constructed through measuring mouse body weight (a) and uterine weight (b). c The expression levels of NFATc1, c-Fos, DC-STAMP, Acp5, Atp6rod2, CTSK were examined using qRT-PCR. The mRNA and protein expression levels of RANKL, OPG, and RANKL/OPG were detected using RT-qPCR (d) and western blotting (e, f), respectively. $\mathbf{g}$ The femur of each mouse were scanned with micro-CT. $\mathbf{h}$ The BV/TV, BS/BV, Tb. Sp, Tb. T and Tb. N of each sample was measured. Sections of femur were stained with H\&E (i) and TRAP (j) staining. $\mathbf{k}$, I The OcS/BS and number of osteoclasts per field of each sample was analyzed. $\mathbf{m}, \mathbf{n}$ Sections of femurs were stained with von Kossa, and calculated the MS/BS (\%). $\mathbf{0}, \mathbf{p}$ Calcein double fluorescent labeling to observe the mouse femur MAR. All experiments were performed at least three times. ${ }^{*} P<0.05$ and ${ }^{* *} P<$ 0.01 compared with the control group. BV/TV: bone volume per tissue volume, BS/BV: bone surface per bone volume, Tb.Sp: trabecular separation, Tb.T: trabecular thickness, Tb.N: trabecular number, OcS/BS: osteoclast surface per bone surface, MS/BS (\%): the ration of mineralized area to bone surface area, MAR: mineral apposition rate

inhibits osteoclastogenesis through downregulating the expression of RANKL and upregulating the expression of OPG in osteoblasts. However, a recent study has shown that PPAR agonists reduced alveolar bone loss in the short term (one week), while promoted osteoclast formation by downregulating OPG expression and upregulating RANKL expression after eight weeks [34], which was similar to our results. Thus, this finding suggests that the effects of T007 on osteoclastogenesis and osteoblastogenesis are possibly driven by a regulatory mechanism involving the OPG/ RANKL/RANK regulatory module.

PPAR $\gamma$, a ligand-dependent nuclear receptor, regulates a variety of physiological and disease processes such as inhibiting inflammatory responses and regulating bone cell differentiation [35, 36]. Former research teams reported that PPAR $\gamma$ can induce osteoclastogenesis but inhibits osteoblast differentiation [37, 38]. Rzonca et al. conveyed that thiazolidinedione-activated PPAR $\gamma$ inhibits osteoblast differentiation [39]. In addition, PPARY overexpression increases RANKL/OPG ratio, leading to reduced bone formation, thereby accelerating OVX-induced bone loss in female mice [40]. Jeon, Kim [41] showed that PPARY activation can downregulate expression and function of Runx2 to inhibit osteoblast differentiation. An in vivo mouse experiment showed that PPAR $\gamma$ can promote osteoclast differentiation through regulating the expression of c-Fos [42]. In this study, we found that PPAR $\gamma$ is increased in RANKL-induced osteoclasts. Moreover, PPAR $\gamma$ overexpression pointedly lessened Runx2 expression level while upregulating the levels of the osteoclastogenesis regulators such as NFATc1 and c-Fos, which indicated that PPAR $\gamma$ is a key factor that hinders osteoblastogenesis and promotes osteoclastogenesis.

We additionally scrutinized the action of PPAR $\gamma$ on RANKL-induced osteoclasts and its underlying mechanisms. Antagonism of PPAR $\gamma$ with T007 promoted ALP expression [43]. The opposite result was obtained in the previous study of PPAR $\gamma$ agonists [44, 45]. Previous studies showed that the class II histone deacetylase 9 (HDAC-9) inhibits osteoclast differentiation and bone resorption by repressing PPARY activity [46]. Similar results were found regarding the levels of factors in
RANKL-induced osteoclasts. T007 decreased the expression levels of PPAR $\gamma$ and osteoclastogenesis-specific genes such as NFATc1, c-Fos and DC-STAMP, and promoted $\beta$-catenin and Runx2 expression levels. NFATc1 and Runx 2 are both determinant transcription factors involved in the regulation of osteoclastogenesis and osteogenic differentiation $[47,48]$. Runx2 was recently reported to upgrade the osteoblastogenesis of MSCs [49]. Here, Runx2 expression was increased, suggesting that T007 promotes osteoblast differentiation. NFATc1 is a major regulator of osteoclast differentiation induced by RANKL and regulates other osteoclast-specific genes including CTSK, c-Fos, Atp6v0d2 and DC-STAMP [50, 51]. In addition, previous studies indicated that DC-STAMP silencing significantly inhibited the formation of multinucleated osteoclast-like cells [52]. Our findings hinted that T007 significantly reduced expression of NFATc1 both at protein and mRNA levels. Equally, T007 downregulated the levels of CTSK, c-Fos, DC-STAMP, Acp5 and Atp6v0d2, indicating that T007 can inhibit RANKL-induced osteoclasts activity. Furthermore, we examined whether T007 could affect the OVX-induced bone loss in vivo. RT-PCR results, micro-CT, HE staining, and von Kossa staining analysis indicated T007 hinders the osteoclastic bone loss in vivo through upregulating OPG expression and downregulating RANKL expression. These results conformed with previous studies showing that metformin markedly increases tibia bone mineral density and reduces TRAPpositive cells in the OVX rats by increasing OPG expression and decreasing RANKL expression to prevent bone loss [53]. In summary, our study signposted that T007 suppresses RANKL-induced osteoclastogenesis and induces osteoblastogenesis in cell and animal studies. These findings may be beneficial for the handling of bone diseases and bone tissue engineering.

\section{Conclusion}

As shown in Additional file 2: Figure S2, T007 reduces PPAR $\gamma$ expression that inhibits the differentiation of osteoclast progenitors into osteoclasts, thus attenuating bone resorption. In osteoclast progenitor, T007 suppresses c-Fos expression, which stimulates osteoclastogenesis. 
Conversely, T007 restrains PPAR $\gamma$ activation that promotes pre-osteoblasts differentiation into osteoblasts and contributes to BMSCs growth by increasing Runx2 expression, thus enhancing bone formation. Consequently, T007 prevents bone loss by tipping in balance of bone remodeling through concerned stimulation of bone resorption and inhibition of bone formation.

\section{Supplementary information}

Supplementary information accompanies this paper at https://doi.org/10. 1186/s12964-019-0442-3.

Additional file 1: Figure S1. T007 regulates the expression of PPARY, CFos and F-actin, promotes the cell apoptosis and blocks the interaction between c-Fos and RANKL in vitro. BMMs were treated with or without $0.6 \mu \mathrm{M}$ of T007. (A) The expression levels of PPARY and c-Fos were detected using immunofluorescence. (B) The effect of T007 on cell apoptosis of osteoclasts was analyzed using flow cytometry. (C) ChIP experiment was used to detect whether T007 can block the binding of RANKL to c-Fos gene. (D, E) Representative images for F-actin ring formation using immunofluorescence. (F) The expression levels of F-actin ring and PPARY were measured using immunofluorescence. (G) The expression of PPARY was detected using IP assay. All experiments were performed at least three times. ${ }^{*} P<0.05$ and ${ }^{*} P<0.01$ compared with the control group.

Additional file 2: Figure S2. A simplified model of the mechanism by which T007 inhibits osteoclastogenesis and osteoblastogenesis. T007 reduces PPARY expression that inhibits osteoclast progenitor's differentiation into osteoclasts, thus attenuating bone resorption. In osteoclast progenitor, T007 suppress c-Fos expression, which stimulates osteoclastogenesis. Conversely, T007 restrains PPARY activation that promotes pre-osteoblasts differentiation into osteoblasts and contributes to BMSCs growth by increasing Runx2 expression, thus enhancing bone formation. Consequently, T007 results in bone loss by tipping in balance of bone remodeling through concerned stimulation of bone resorption and inhibition of bone formation.

\section{Abbreviations}

BMM: Bone marrow-derived macrophages; MAPK: Mitogen-activated protein kinase; NFATc1: Nuclear factor of activated T cells 1;

OPG: Osteoproteoprotein; OVX: Ovariectomy; PBS: Phosphate buffered saline: PPARY: Peroxisome proliferator-activated receptor-gamma; RANKL: Receptor activator of nuclear factor-kB ligand; RIPA: Radioimmunoprecipitation assay

\section{Acknowledgments}

Not applicable.

\section{Authors' contributions}

SW, XL and SF designed research. XL, LN, ZX, JM, XZ, and GW carried out experiments. ZX, XL, XZ, GW, JM and XW analyzed data. SW, JM and SF interpreted results of experiments. $P Q$, TY and $H W$ prepared the figures. $X L$, $\mathrm{LN}$, and JM wrote the manuscript. All authors reviewed the manuscript. All authors read and approved the final manuscript.

\section{Funding}

This study was sponsored by National Key R\&D Program of China (No. 2018YFC1105200), the Key Research and Development Plan in Zhejiang Province (No. 2018C03060), Natural Science Fund of Zhejiang Province (LY18H060001), and National Nature Science Fund of China (81772387, 81601925). No benefits in any form have been or will be received from a commercial party related directly or indirectly to the subject of this study.

\section{Availability of data and materials}

All data generated or analyzed during this study are included in this published article.
Ethics approval and consent to participate

Not applicable.

\section{Consent for publication}

Not applicable.

\section{Competing interests}

The authors declare that they have no competing interests.

\section{Author details}

'Department of Orthopaedic Surgery, Sir Run Run Shaw Hospital, Zhejiang University School of Medicine, 3 East Qingchun Road, Hangzhou 310016, China. ${ }^{2}$ Key Laboratory of Musculoskeletal System Degeneration and Regeneration Translational Research of Zhejiang Province, Hangzhou 310016, China. ${ }^{3}$ First Clinical Medical College, Wenzhou Medical University, Wenzhou 325035, China. ${ }^{4}$ The Third Hospital of Hebei Medical University, Shijiazhuang 050051, China.

Received: 3 June 2019 Accepted: 20 September 2019

Published online: 26 October 2019

\section{References}

1. Chen G, Deng C, Li YP. TGF- $\beta$ and BMP signaling in osteoblast differentiation and bone formation. Int J Biol Sci. 2012;8(2):272-88.

2. Soltanoff CS, Yang S, Chen W, Li YP. Signaling networks that control the lineage commitment and differentiation of bone cells. Crit Rev Eukaryot Gene Expr. 2009;19(1):1-46.

3. De Martinis M, Di Benedetto MC, Mengoli LP, Ginaldi L. Senile osteoporosis: is it an immune-mediated disease? Inflamm Res. 2006;55(10):399-404.

4. Stevens JA, Rudd RA. The impact of decreasing U.S. hip fracture rates on future hip fracture;estimates. Osteoporos Int. 2013;24(10):2725-8.

5. Bezerra MC, Carvalho JF, Prokopowitsch AS, Pereira RM. RANK, RANKL and osteoprotegerin in arthritic bone loss. Braz J Med Biol Res. 2005; 38(2):161-70.

6. Boyle WJ, Simonet WS, Lacey DL. Osteoclast differentiation and activation. Nature. 2003;423(6937):337.

7. Boyce BF, Xing L. The RANKL/RANKNOPG pathway. Curr Osteoporos Rep. 2007;5(3):98-104.

8. Leibbrandt A, Penninger JM. RANKL/RANK as key factors for osteoclast development and bone loss in arthropathies. Adv Exp Med Biol. 2009;649: 100-13.

9. Yamashita T, Yao Z, Li F, Zhang Q, Badell IR, Schwarz EM, et al. NF-kappaB p50 and p52 regulate receptor activator of NF-kappaB ligand (RANKL) and tumor necrosis factor-induced osteoclast precursor differentiation by activating C-Fos and NFATC1. J Biol Chem. 2007;282(25):18245-53.

10. Xue JB, Zhan XL, Wang WJ, Yan YG, Liu C. OPG rs2073617 polymorphism is associated with upregulated OPG protein expression and an increased risk of intervertebral disc degeneration. Exp Ther Med. 2016;12(2):702-10.

11. Joseph DJ, Ichikawa S, Econs MJ. Mosaicism in osteopathia striata with cranial sclerosis. J Clin Endocrinol Metab. 2010;95(4):1506-7.

12. Lacey DL, Boyle WJ, Simonet WS, Kostenuik PJ, Dougall WC, Sullivan JK, et al. Bench to bedside: elucidation of the OPG-RANK-RANKL pathway and the development of denosumab. Nat Rev Drug Discov. 2012;11(5):401-19.

13. Liu C, Feng T, Zhu N, Liu P, Han X, Chen M, et al. Identification of a novel selective agonist of PPARy with no promotion of adipogenesis and less inhibition of osteoblastogenesis. Sci Rep. 2015;5:9530.

14. Shu L, Beier E, Sheu T, Zhang H, Zuscik MJ, Puzas EJ, et al. High-fat diet causes bone loss in young mice by promoting Osteoclastogenesis through alteration of the bone marrow environment. Calcif Tissue Int. 2015;96(4):313-23.

15. Zheng T, Kang JH, Sim JS, Kim JW, Koh JT, Chan SS, et al. The farnesoid X receptor negatively regulates osteoclastogenesis in bone remodeling and pathological bone loss. Oncotarget. 2017;8(44):76558-73.

16. Janani C, Ranjitha Kumari BD. PPAR gamma gene - a review. Diabetes Metab Syndr. 2015;9(1):46-50.

17. Chiu CY, Sun SC, Chiang CK, Wang CC, Chan DC, Chen HJ, et al. Plasticizer Di (2-ethylhexyl) phthalate interferes with Osteoblastogenesis and Adipogenesis in a mouse model. J Orthop Res. 2018;36(4):1124-34.

18. Wu YX, Sun Y, Ye YP, Zhang P, Guo JC, Huang JM, et al. Iguratimod prevents ovariectomy-induced bone loss and suppresses osteoclastogenesis via inhibition of peroxisome proliferator-activated receptor- $\gamma$. Mol Med Rep. 2017;16(6):8200-8 
19. Brust R, Lin H, Fuhrmann J, Asteian A, Kamenecka TM, Kojetin DJ. Modification of the Orthosteric PPARy covalent antagonist scaffold yields an improved dual-site allosteric inhibitor. ACS Chem Biol. 2017;12(4):969.

20. Lee G, Elwood F, McNally J, Weiszmann J, Lindstrom M, Amaral K, et al. T0070907, a selective ligand for peroxisome proliferator-activated receptor gamma, functions as an antagonist of biochemical and cellular activities. J Biol Chem. 2002;277(22):19649-57.

21. Zaytseva YY, Wallis NK, Southard RC, Kilgore MW. The PPARgamma antagonist T0070907 suppresses breast cancer cell proliferation and motility via both PPARgamma-dependent and -independent mechanisms. Anticancer Res. 2011;31(3):813-23.

22. Choudhary R, Li H, Winn RA, Sorenson AL, Weiser-Evans MC, Nemenoff RA. Peroxisome proliferator-activated receptor- $\gamma$ inhibits transformed growth of non-small cell lung Cancer cells through selective suppression of snail. Neoplasia. 2010;12(3):224-34

23. Schaefer KL, Wada K, Takahashi H, Matsuhashi N, Ohnishi S, Wolfe MM, et al. Peroxisome proliferator-activated receptor $\gamma$ inhibition prevents adhesion to the extracellular matrix and induces Anoikis in hepatocellular carcinoma cells. Cancer Res. 2005;65(6):2251-9.

24. Han G, Zuo J, Holliday LS. Specialized roles for actin in osteoclasts: unanswered questions and therapeutic opportunities. Biomolecules. 2019; $9(1): 17$

25. Boyce BF, Xing L. Biology of RANK, RANKL, and osteoprotegerin. Arthritis Res Ther. 2007;9 Suppl 1:S1.

26. Boyce BF, Xing L. Functions of RANKL/RANK/OPG in bone modeling and remodeling. Arch Biochem Biophys. 2008;473(2):139-46.

27. Miyazaki T, Tokimura F, Tanaka S. A review of denosumab for the treatment of osteoporosis. Patient Prefer Adherence. 2014;8(8):463-71.

28. Bamias A, Kastritis E, Bamia C, Moulopoulos LA, Melakopoulos I, Bozas $\mathrm{G}$, et al. Osteonecrosis of the jaw in cancer after treatment with bisphosphonates: incidence and risk factors. J Clin Oncol. 2005;23(34): 8580-7.

29. Ohazama A, Courtney JM, Sharpe PT. Opg, Rank, and Rankl in tooth development: co-ordination of odontogenesis and osteogenesis. J Dent Res. 2004;83(3):241-4.

30. Dougall WC, Chaisson M. The RANK/RANKL/OPG triad in cancer-induced bone diseases. Cancer Metastasis Rev. 2006;25(4):541-9.

31. Kühn MC, Willenberg HS, Schott M, Papewalis C, Stumpf U, Flohé S, et al. Adipocyte-secreted factors increase osteoblast proliferation and the OPG/ RANKL ratio to influence osteoclast formation. Mol Cell Endocrinol. 2012; 349(2):180-8.

32. Pan QJ, Hu SY, Guo HQ, Zhang WH, Zhang X, Chen W, et al. Liquid-based cytology and human papillomavirus testing: a pooled analysis using the data from 13 population-based cervical cancer screening studies from China. Gynecol Oncol. 2014;133(2):172-9.

33. Lee MJ, Lee SY, Park SH, Ahn DW. Differential expression of RANKL and OPG by the PPAR gamma agonist rosiglitazone in osteoblasts. J Korean Soc Osteoporos. 2010;8(1):47-55.

34. Qiao W, Wang C, Huang W, Hu Y, Song Y. Peroxisome proliferator-activated receptor $\gamma$ plays dual roles on experimental periodontitis in rats. J Clin Periodontol. 2018;45(5):514-23.

35. Dantas AT, Pereira MC, de Melo Rego MJ, da Rocha LF Jr, Pitta Ida R, Marques CD, et al. The role of PPAR gamma in systemic sclerosis. PPAR Res. 2015;2015:124624

36. Man B, Wang $H$, Xiang $X$, Wang $R$, Yun $Y$, Gong L. Phylogenetic diversity of culturable fungi in the Heshang cave, Central China. Front Microbiol. 2015:6:1158

37. Akune T, Ohba S, Kamekura S, Yamaguchi M, Chung UI, Kubota N, et al. PPARgamma insufficiency enhances osteogenesis through osteoblast formation from bone marrow progenitors. J Clin Invest. 2004;113(6):846-55.

38. Wan Y. PPARy in bone homeostasis. Trends Endocrinol Metab. 2010;21(12): $722-8$.

39. Rzonca SO, Suva LJ, Gaddy D, Montague DC, Lecka-Czernik B. Bone is a target for the antidiabetic compound rosiglitazone. Endocrinology. 2004 145(1):401-6.

40. Cho SW, Yang JY, Her SJ, Choi HJ, Jung JY, Sun HJ, et al. Osteoblast-targeted overexpression of PPARy inhibited bone mass gain in male mice and accelerated ovariectomy-induced bone loss in female mice. J Bone Miner Res. 2011;26(8):1939-52.

41. Jeon MJ, Kim JA, Kwon SH, Kim SW, Park KS, Park SW, et al. Activation of peroxisome proliferator-activated receptor-gamma inhibits the Runx2- mediated transcription of osteocalcin in osteoblasts. J Biol Chem. 2003; 278(26):23270-7.

42. Wan Y, Chong LW, Evans RM. PPAR- $\gamma$ regulates osteoclastogenesis in mice. Nat Med. 2007:13(12):1496-503.

43. Haarhaus M, Brandenburg V, Kalantar-Zadeh K, Stenvinkel P, Magnusson P. Alkaline phosphatase: a novel treatment target for cardiovascular disease in CKD. Nat Rev Nephrol. 2017;13(7):429-42.

44. Koufany M, Chappard D, Netter P, Bastien C, Weryha G, Jouzeau JY, et al. The peroxisome proliferator-activated receptor $\gamma$ agonist pioglitazone preserves bone microarchitecture in experimental arthritis by reducing the interleukin-17-dependent osteoclastogenic pathway. Arthritis Rheum. 2013; 65(12):3084-95.

45. Qiao W, Wang C, Huang W, Hu Y, Song Y. PPARy plays dual roles on experimental periodontitis in rats. J Clin Periodontol. 2018;45(5):514-23.

46. Jin Z, Wei W, Huynh H, Wan Y. HDAC9 inhibits Osteoclastogenesis via mutual suppression of PPARgamma/RANKL signaling. Mol Endocrinol. 2015; 29(5):730-8.

47. James AW. Review of Signaling Pathways Governing MSC Osteogenic and Adipogenic Differentiation. Scientifica (Cairo). 2013;2013:684736.

48. Chen S, Jin G, Huang KM, Ma JJ, Wang Q, Ma Y, et al. Lycorine suppresses RANKL-induced osteoclastogenesis in vitro and prevents ovariectomyinduced osteoporosis and titanium particle-induced osteolysis in vivo. Sci Rep. 2015;5:12853.

49. Zhang L, Su P, Xu C, Chen C, Liang A, Du K, Peng Y, Huang D. Melatonin inhibits adipogenesis and enhances osteogenesis of human mesenchymal stem cells by suppressing PPARy expression and enhancing Runx2 expression. J Pineal Res. 2010;49(4):364-72.

50. Kim Y, Sato K, Asagiri M, Morita I, Soma K, Takayanagi H. Contribution of nuclear factor of activated $T$ cells $\mathrm{Cl}$ to the transcriptional control of immunoreceptor osteoclast-associated receptor but not triggering receptor expressed by myeloid cells-2 during osteoclastogenesis. J Biol Chem. 2005; 280(38):32905-13.

51. Kim K, Lee SH, Ha Kim J, Choi Y, Kim N. NFATc1 induces osteoclast fusion via up-regulation of Atp6v0d2 and the dendritic cell-specific transmembrane protein (DC-STAMP). Mol Endocrinol. 2008;22(1):176-85.

52. Kukita T, Wada N, Kukita A, Kakimoto T, Sandra F, Toh K, et al. RANKLinduced DC-STAMP is essential for osteoclastogenesis. J Exp Med. 2004; 200(7):941-6.

53. Mai QG, Zhang ZM, Xu S, Lu M, Zhou RP, Zhao L, et al. Metformin stimulates osteoprotegerin and reduces RANKL expression in osteoblasts and ovariectomized rats. J Cell Biochem. 2011;112(10):2902-9.

\section{Publisher's Note}

Springer Nature remains neutral with regard to jurisdictional claims in published maps and institutional affiliations.

Ready to submit your research? Choose BMC and benefit from:

- fast, convenient online submission

- thorough peer review by experienced researchers in your field

- rapid publication on acceptance

- support for research data, including large and complex data types

- gold Open Access which fosters wider collaboration and increased citations

- maximum visibility for your research: over $100 \mathrm{M}$ website views per year

At $\mathrm{BMC}$, research is always in progress.

Learn more biomedcentral.com/submissions 